IZA DP No. 6851

Trust and Trustworthiness under the Prospect Theory: A Field Experiment in Vietnam

Quang Nguyen

Marie Claire Villeval

Hui Xu

September 2012

Forschungsinstitut zur Zukunft der Arbeit Institute for the Study of Labor 


\title{
Trust and Trustworthiness under the Prospect Theory: A Field Experiment in Vietnam
}

\author{
Quang Nguyen \\ Nanyang Technological University \\ Marie Claire Villeval \\ University of Lyon, GATE, CNRS \\ and IZA \\ Hui Xu \\ University of Lyon, GATE, CNRS \\ Discussion Paper No. 6851 \\ September 2012 \\ IZA \\ P.O. Box 7240 \\ 53072 Bonn \\ Germany \\ Phone: +49-228-3894-0 \\ Fax: +49-228-3894-180 \\ E-mail: iza@iza.org
}

\begin{abstract}
Any opinions expressed here are those of the author(s) and not those of IZA. Research published in this series may include views on policy, but the institute itself takes no institutional policy positions.

The Institute for the Study of Labor (IZA) in Bonn is a local and virtual international research center and a place of communication between science, politics and business. IZA is an independent nonprofit organization supported by Deutsche Post Foundation. The center is associated with the University of Bonn and offers a stimulating research environment through its international network, workshops and conferences, data service, project support, research visits and doctoral program. IZA engages in (i) original and internationally competitive research in all fields of labor economics, (ii) development of policy concepts, and (iii) dissemination of research results and concepts to the interested public.
\end{abstract}

IZA Discussion Papers often represent preliminary work and are circulated to encourage discussion. Citation of such a paper should account for its provisional character. A revised version may be available directly from the author. 
IZA Discussion Paper No. 6851

September 2012

\section{ABSTRACT}

\section{Trust and Trustworthiness under the Prospect Theory: A Field Experiment in Vietnam}

We study the influence of risk and time preferences on trust and trustworthiness by conducting a field experiment in Vietnamese villages and by estimating the parameters of the Cumulative Prospect Theory and of quasi-hyperbolic time preferences. We find that while probability sensitivity or risk aversion do not affect trust, loss aversion influences trust indirectly by lowering the expectations of return. Also, more risk averse and less present biased participants are found to be trustworthier. The experience of receiving remittances influences behavior and a longer exposure to a collectivist economy tend to reduce trust and trustworthiness.

JEL Classification: C91, C93, D81, D90, O10, O53

Keywords: trust, trustworthiness, risk preferences, time preferences, Cumulative Prospect Theory, Vietnam, field experiment

Corresponding author:

Marie Claire Villeval

GATE (Groupe d'Analyse et de Théorie Economique)

CNRS - University of Lyon

93, Chemin des Mouilles

F-69130 Ecully

France

E-mail: villeval@gate.cnrs.fr

\footnotetext{
${ }^{*}$ We are grateful to participants at the Asia-Pacific meeting of the Economic Science Association in Xiamen and at the ASFEE workshop on field experiments for useful comments on an earlier version of this paper. This research was supported by a PEPS grant from the Institute of Social Science at National Center for Scientific Research (CNRS), France. We would like to thank our research coordinators Tran Minh Ngoc and Vu Hung Cuong, our research assistants at the Vietnam Economics Institute and Cantho Stastical Department for their excellent support in conducting the experiments.
} 
"Virtually every commercial transaction has within itself an element of trust, certainly any transaction conducted over a period of time. It can be plausibly argued that much of the economic backwardness in the world can be explained by the lack of mutual confidence".

Kenneth Arrow (1972)

\section{INTRODUCTION}

A large literature shows that trust contributes to growth and development, political success, and social well-being (Knack and Kiefer, 1997; La Porta et al., 1997; Zak and Knack, 2001; Guiso et al., 2009;Algan and Cahuc, 2010). Trust reduces dramatically transaction costs and contributes to the efficiency of economic organizations (Fukuyama, 1995). In contrast, low trust increases demand for regulation (Aghion et al., 2010) and low levels of trustworthiness hinder the development of social capital necessary for economic development (Neace, 2004). Trust and trustworthiness are also necessary for democratization (Tilly, 2005). Better understanding the determinants of trust and trustworthiness is therefore fundamental.

We investigate how trust and trustworthiness relate to risk aversion, loss aversion, time preferences, the experience of receiving gifts, and institutions. To this end, we conducted an artefactual field experiment based on the trust game (Berg et al., 1995) in villages in the North and the South of Vietnam. All participants in our experiment had previously participated in the 2002 Vietnam Household Living Standard Survey (VHLSS 2002), which allows us to match behavior with survey data. We use a standard trust game in which trust is measured by the amount sent by a truster to a trustee while the amount returned by the trustee measures his/her trustworthiness.

Although trusting behavior has been widely studied either through value surveys or experimentally (Glaeseret al., 2000), there is no consensus on its links with basic human preferences (Camerer, 2003; Fehr, 2009). Both behavioral studies (Andreoni and Miller, 2002; Cox, 2004; Ashraf et al., 2006) and neuroscientific studies (Kosfeld et al. 2005; Baumgartner et al., 2008) have shown that social preferences, and in particular betrayal aversion (Bohnet and Zeckhauser, 2004; Bohnet et al., 2008), play a major role in trusting behavior that is distinct to that of risk-taking. But this does not exclude that risk preferences still influence behavior 
(Ben-Ner and Putterman, 2001; Cook and Cooper, 2003). Indeed, trusting others means making oneself vulnerable to a counterpart who can decide to reciprocate or betray, which creates uncertainty. The literature has delivered mixed evidence on the influence of risk attitudes in the trust game. Karlan (2005) and Schechter (2007) have found that higher trust correlates with less risk aversion, even after controlling for altruism. ${ }^{1}$ In contrast, Eckel and Wilson (2004), Ashraf et al. (2006), Houser et al. (2010), and McEvily et al. (2012) have not found any correlation between trust and behavioral measures of risk attitudes.

The unclear link between risk attitudes and trusting behavior in the literature may result from the fact that most measures used in these studies involve lotteries that may not capture the attitudes towards strategic uncertainty. It is also the case that, as mentioned by Houser et al. (2008), many studies do not elicit individual risk preferences but simply compare the distributions of decisions in trust and risk games. ${ }^{2}$ Finally, the studies that elicit individual risk attitudes assume that individuals behave according to the expected utility theory and only characterize risk preferences by choices of lotteries in the domain of gains. ${ }^{3}$ Yet, this assumption has been frequently challenged and the prospect theory offers a richer approach to risk attitudes (Kahneman and Tversky, 1979; Tversky and Kahneman, 1992; Wakker, 2010). For example, if people are loss averse, analyzing the link between trust and risk preferences only based on the concavity of the utility function will bias the estimates. Thus, to establish the role of risk attitudes on trust it is important to apply a more general framework than the expected utility (EU) theory.

One novelty of our study is that we expand the measurement of risk preferences to incorporate

${ }^{1}$ Controlling for betrayal aversion, Fehr (2009) found also a significant negative relationship between self-reported risk preferences and self-reported trust. Naef and Schupp (2009) find that survey and experimental measures of trust correlate with self-reported risk attitudes.

${ }^{2}$ In Ashraf et al. (2006), people make choices between a risky gamble with a $50 \%$ chance of winning a prize and a deterministic payoff whose amount was varied. In Schechter (2007) and McEvily et al. (2012), the risk game is similar to the trust game: players choose the amount of a bet which return depends on the roll of a die. Snijders and Keren (1998) measure risk by varying the payoff structure in the trust game. Bohnet and Zeckhauser (2004) and Bohnet et al. (2008) compare behavior facing social risk and state risk; risk acceptance is measured by asking players their minimum acceptable probability for securing the high payoff that lead them to accept to a risky payoff. ${ }^{3}$ In Eckel and Wilson (2004), individual risk attitudes are elicited through choices between lotteries, based on the Holt and Laury (2002) procedure. But if these attitudes do not predict behavior in the trust game, they do not predict either decisions in their risk game in which subjects choose between lotteries and certain amounts. Houser et al. (2008) also elicit individual risk attitudes with the Holt and Laury procedure and show that they predict behavior in risk games but not in trust games. In contrast to these studies, Karlan (2005) proxies risk attitudes by comparisons of the participants' borrowings and savings in a microcredit program. 
prospect theory, like in Tanaka et al. (2010), and we measure the correlation between trust on the one hand, and the curvature of the utility function, nonlinear probability weighting and loss aversion, on the other hand. This approach is crucial because in the context of trust, EU theory may be inadequate if participants evaluate the possible outcomes of their decisions relative to a reference point (that may differ in the North and the South of Vietnam) or if there is an endowment effect; in this case, due to loss aversion, individuals may prefer to keep their initial endowment rather than taking the risk of losing their money.

As far as we know, the literature is silent about the links between behavior in the trust game and time preferences. We provide the first analysis of the role of patience in this game. Our intuition is that in real life settings, more patient people may be more likely to behave in ways that preserve long-term mutually beneficial relationships. Although the trust game is played one-shot, this type of preference may influence players' behavior. Patience may motivate individuals to trust more and to return more instead of taking profits right away that may be harmful to the long-term cooperation between villagers in everyday life. Recent studies of time preferences have also shown that it is too restrictive to measure time preferences by an exponential discount rate (Tanaka et al., 2010). For that reason, we estimate a quasi-hyperbolic function following Benhabib et al. (2010) and relate discounting rate and present bias to trust and trustworthiness. If trusting others is risky because the return is uncertain, experience with this type of situation in real life may possibly change the player's perception of the game. Another novelty of our approach is that we study whether trust and trustworthiness are influenced by the experience of receiving gifts from others in real life. We use the remittances received by the household as a proxy for such an experience. While international remittances are typically not associated with a need for the receiver to reciprocate (on the contrary, they may be viewed as the return by the migrant in response to the initial help by the family, see Stark and Lucas, 1988), domestic remittances are more directly associated with gift exchange relationships and a norm of reciprocity. Therefore, receiving international or domestic remittances is expected to influence differently both trust and reciprocity. 
Finally, since trust and the institutional structure of a country may be strongly tied together (Hardin, 1992; Knack and Keefer, 1997), we conducted the experiment in two regions of the same country that are characterized by a different political and economic history. ${ }^{4}$ Indeed, the North of Vietnam has a much longer communist history than the South since its establishment in 1945, while South Vietnam was under the French then the U.S. regime between 1945 and 1975. The two states were merged in 1975 and unified politically as the socialist republic of Vietnam. Since 1986, the country has initiated more market-oriented economic reforms ("Doi Moi"). Because a significant number of participants in our experiment were born before 1975, we are able to verify whether the effect of risk and time preferences on the trust game behavior differ according to the length of exposure to a collectivist culture.

Our main findings show that while trust is driven by the expectation of a higher return from the trustee, it is unaffected by probability weighting, by the concavity of the utility function, and by time preferences. However, loss aversion impacts trust indirectly through its negative impact on the expectations of return. We also find that individuals from households who have received higher international remittances are more trustful than the other participants. Regarding trustworthiness, we show that more risk averse and less present biased individuals are trustworthier, while loss aversion and time discounting have no effect on reciprocity. In contrast to international remittances, higher domestic remittances increase the rate of return, which is consistent with the fact that domestic remittances are typically embedded in a larger network of social relationships and are associated with some expectation of return. As for the institutional and cultural environment, we found that in the North of Vietnam, trusters have lower expectations of return than those in the South, older individuals are significantly less trustful than younger individuals, and trustees return significantly less than those in the South of the country. This could be due to a longer exposure of Northerners to a collectivist culture while people in the South have perhaps adopted more the values of market economy.

\footnotetext{
${ }^{4}$ The literature includes many cross-country comparisons on trust (e.g., Yamagishi et al., 1998; Carpenter et al., 2004; Ashraf et al., 2006; Bohnet et al. 2008), but within-country comparisons are rare (e.g. Bahri and Wilson, 2004; Alesina and Fuchs-Schündeln, 2007; Tanaka et al., 2010; Brosig-Bosch et al., 2012).
} 
We proceed with the remainder of this paper as follows: Section 2 describes the experimental design and procedures. Section 3 analyzes the results and Section 4 discusses them and concludes.

\section{EXPERIMENTAL DESIGN AND IMPLEMENTATION}

\subsection{The three tasks}

The experiment was conducted in Vietnam in July-August 2010. Each session was comprised of three different decision-making tasks, performed in sequence: a risk elicitation task, a time preference elicitation task, and a trust game. The general design of the experiment is close to that

of Tanaka et al. (2010). ${ }^{5}$ Since our study focuses on trust, we introduce first the trust game, before introducing the other tasks. All the instructions can be found in Appendix 1.

\section{The Trust game}

The trust game is based on the game of Berg et al. (1995) in which we apply the strategy method. ${ }^{6}$ All the players act first as trusters (player A) and then as trustees (player B). Each player is initially endowed with KVND $20 .^{7}$ In the first stage, player A decides how much of his endowment to send $(x)$ to player B, among the following choices: KVND 0, 5, 10, 15 and 20. This restricted number of options aims at simplifying the game. Any amount sent is multiplied by three before it reaches player B. Like in Eckel and Wilson (2004) and in Ashraf et al. (2006), we also ask player A to report how much return he expects from player B conditional on the amount he sent to him, as we expect that part of trust is calculative (Hardin, 2002). For the sake of simplicity, belief elicitation is not incentivized. In the second stage, all players act as players Band have to decide how much they are willing to return to player A $(y)$ for each possible amount sent by A. In order to facilitate the calculation of payoffs, participants are given tables with

\footnotetext{
5 One difference is that their field experiment started with the trust game, followed by the risk game, and then the time preference game, whereas in ours, the trust game was played at the end. The main consideration of the order change is that the trust experiment is the most difficult one to play. The first two games can provide participants some initiation into the experimental environment, making it easier for them to understand the trust game.

${ }^{6}$ In their survey of the literature,Brandts and Charness (2011) show that in this type of games the strategy method produces similar behavior to the direct-response one. This is confirmed by the meta-analysis of the trust game by Johnson and Mislin (2011).

7 VND refers to Vietnamese Dongs; K represents thousand. On average, the mean daily income for unskilled work in Vietnam in 2010 was around KVND 35 (around 2 U.S. Dollars).
} 
with examples for each possible amount sent by player A.

Before the game starts, each participant is given randomly a tag colored either red or white. At the end of the game, once all players have made their decisions in both roles, we toss a coin. If head comes up, the participants with red tags are assigned the role of player A and those with white tags the role of player B. We pair players randomly and we implement the players' actual decisions corresponding to their role. The final payoff of player $\mathrm{A}$ is $(20-x+y)$ and that of player B is $(20+3 * x-y)$.

\section{Elicitation of risk preferences}

To measure the three prospect theory parameters that characterize risk attitudes (utility concavity, probability weighting, and loss aversion), we ask participants to make decisions in three series of paired lotteries totaling 33 questions. Series 1 includes 12 questions, series 214 questions, and series 37 questions. $^{8}$ Each question is a choice between two binary lotteries, A or B. Each decision is made by choosing a reward with a certain probability represented by a number of balls, with each ball marked by a unique number from 1 to 10 . In the first series, plan A is fixed, at KVND 40 with probability 0.3 and KVND 10 with probability 0.7 . Plan B is half fixed and half changing. The payoff is always KVND 5 with probability 0.9 and, as one moves down the rows, the payoff is from KVND 68 to KVND 600 with probability 0.1. Series 2 is similar, but with different payoffs and probabilities. Plan A is always fixed, at KVND 40 with probability 0.9 and KVND30 with probability 0.1 . Plan B is mixed. The payoff is KVND 5 with probability 0.3 and, moving down the rows, from KVND 54to 130 with probability 0.7 . In series 1 and 2, individuals are expected to choose plan $\mathrm{A}$ in the first row, and as the high potential payoff increases in plan B down the rows, to switch to preferring B to A. A very risk-averse person should switch to plan B later than a risk-neutral one.

To address loss aversion, series 3 involves both gains and losses in both plan A and plan B. In either plan the probabilities of gains and losses are the same: 0.5 . The differences between plan

\footnotetext{
8 We did not include two questions from Tanaka et al. (2010) for which the monetary stakes were extremely high. This should not affect significantly the estimation of the parameters.
} 
A and plan B lie in two points: first, in plan B, the gains and losses are all much larger than in plan A. Second, in plan B, the amount of gains is always KVND 30, while the amount that can be lost decreases from KVND 21 to 11, as one moves down the rows. In plan A, the amount of gains decreases and the amount of losses increases across rows, with the gains varying from KVND 5 to 1 and the losses varying from KVND 4 to 8 . The later they switch from A to B, the more averse individuals are to losses.

In all three series, we enforce monotonic switching by asking participants at which question they would "switch" from plan A to plan B. They can switch starting with the first question and it is made clear in the examples given in the instructions that they do not have to switch at all if they do not want to. After they completed the three series of questions, a participant is selected to draw a numbered ball from a bingo cage with 33 numbered balls, to determine which row of choice will be played for real money. Then, we put 10 balls in the cage. Another participant selected as before draws one ball randomly to determine the outcome of the lottery.

We use cumulative prospect theory (Tversky and Kahneman, 1992) and the one-parameter form of Prelec's axiomatically-derived weighting function (1998). $U(x, p ; y, q)$ represents the expected prospect value over binary prospects consisting of outcome $x$ with probability $p$ and outcome $y$ with probability $q$. Given this setup, we define the prospect theory utility as follows:

$$
\begin{aligned}
& U(x, p ; y, q)=w^{+}(p+q) v(x)+w^{+}(q)(v(y)-v(x)) \text { if } 0<x<y \\
& U(x, p ; y, q)=w^{-}(p+q) v(x)+w(q)^{-}(v(y)-v(x)) \text { if } y<x<0 \\
& U(x, p ; y, q)=w^{-}(p) v(x)+w^{+}(q)(v(y) \text { if } \quad x<0<y
\end{aligned}
$$

where $v(x)$ denotes the power value function, with

$$
\begin{aligned}
& v(x)=x^{\sigma} \quad \text { for } \quad x>0 \\
& v(x)=-\lambda\left(-x^{\sigma}\right) \quad \text { for } \quad x<0
\end{aligned}
$$

and

$$
w(p)=\exp \left[-(\ln p)^{\alpha}\right]
$$

$\sigma$ represents the concavity of the power value function. An individual is risk-neutral if $\sigma=0$, risk 
averse if $\sigma>0$ and risk lover if $\sigma<0 . \lambda$ represents the degree of loss aversion, with higher values of $\lambda$ associated with higher loss aversion. The probability weighting function is linear if $\alpha=1$ (as in the EU theory). If $\alpha>1$, the weighting function is S-shaped (the individual underweights small probabilities and overweighs large probabilities). If $\alpha<1$, it is inverted S-shaped (s/he overweighs small probabilities and underweights large probabilities). We use Prelec's weighting function because it is flexible enough to accommodate the cases where individuals have either inverted-S or S-shaped weighting functions, and has fit previous data reasonably well. If $\alpha=1$ and $\lambda \neq 1$, the EU theory is not rejected.

Tables A2 and A3 in Appendix 3 present the predicted values of the parameters for the curvature of the utility function $(\sigma)$ and for the probability sensitivity in Prelec's weighting function $(\alpha)$ for all possible combinations of switching points in series 1 and 2. In these Tables, "never" indicates the cases in which a participant never switched to plan B. ${ }^{9}$ Similarly Table A4 in Appendix 3 presents the estimates of the ranges of the loss aversion parameter, $\lambda$, for three possible values of $\sigma(0.2,0.6$ and 1$)$.

\section{Elicitation of time preferences}

To measure the quasi-hyperbolic discounting parameters that characterize time preferences (time discounting and present bias), we ask participants to make 75 decisions between receiving money either tomorrow or at specified times in the future. Each question is a choice between two plans. Plan A always offers to receive smaller rewards tomorrow ("Receive VND $x$ tomorrow") while plan B offers larger rewards some time in the future ("Receive VND $y$ in $t$ days"). We use 15 combinations of $y$ and $t$ that define 15 types of plan B. For each $(y, t)$ combination, $x$ increases as rows move on, equaling to $1 / 6,1 / 3,1 / 2,2 / 3$, and $5 / 6$ of the value of $y$. In other words, in each type of plan B, plan A changes with an increasing payoff across five choices. The rewards $x$ and $y$ vary between KVND 5 and 250 and between KVND 30 and 300 respectively. The time delay $t$ varies from three days to three months. In plan A the payment date is tomorrow so that

\footnotetext{
9 Suppose a participant switched from plan A to plan B at the second question in series 1 and third question in series 2. The lower and higher bounds for $\sigma$ are $(1.16,1.29)$, and the lower and upper bounds for $\alpha$ are $(0.56,0.64)$. The mean values of lower and upper bounds indicate that the value of $(\sigma, \alpha)$ for this participant is $(1.2,0.6)$.
} 
regardless of the plan, the participants have to come back to receive their earnings. ${ }^{10}$ The earlier switchers from B to A are less patient.

In all 15 sets of five questions, we enforce monotonic switching by asking participants at which question they would "switch" from plan B to plan A. After all participants completed the 75 questions, we put 75 balls in a bingo cage and one ball is randomly drawn by a participant to select a question which will determine how much money they earned and when this money would be delivered. We then ask the participants to have a discussion about to whom the money should be entrusted until they pick it up on the delivered date. The selected entrusted persons were village heads, commune officers, etc. For each participant, we put the money they earned in an envelope and wrote down their name, the amount of money they should receive, and the date they should pick it up from the entrusted person. The entrusted person would keep all the envelopes until the pick-up date.

These pairwise choices permit estimation of the three-factor model developed by Benhabib et al. (2010). The model values a reward of $y$ at time $t$ according to $y D(y, t)$ where
$y \mathrm{D}(y, t)=y$
if $t=0$
$y \mathrm{D}(y, t)=\beta(1-(1-\theta) r t)^{\frac{1}{1-\theta}} y \quad$ if $t>0$

The three factors $r, \beta$ and $\theta$ separate conventional time discounting $(r)$, present-bias $(\beta)$ and hyperbolicity $(\theta)$ of the discount function $\mathrm{D}(y, t)$. In this study, we assume $\theta$ equal to 1 and estimate $\beta$. Our model specification for time preferences is thus based on the quasi-hyperbolic discounting framework. A higher value of $\beta$ means that the individual is less present biased.

\subsection{Experimental procedures}

Our field experiment was conducted in eight villages in Vietnam: four villages of two provinces in the North and four villages of two provinces in the South. ${ }^{11}$ Participants were members of

\footnotetext{
10 This is another difference with Tanaka et al. (2010) in which the earliest date was today.This avoids that some participants choose plan A not because they are impatient but because they do not trust the experimenters on receiving money in the future or because they want to minimize transaction costs.

11 In the North (Red River Delta), the villages are Yen Lac Truang and Yen Lac Lienchau in VinhPhuc province and Thai Hoa and Diem Dien in Thai Binh province. In the South (Mekong Delta), the villages are Thot Not and Co Do Trung in Can Tho province and TraVinhThanh and PhuocHao in TraVinh province.These villages are different
} 
households who were previously interviewed during the 2002 Vietnam Household Living Standard Surveys (VHLSS2002). This procedure limits the risk of self-selection in the experiment, which is especially important to study trust, risk, and time preferences. Research coordinators from the Vietnam Institute of Economics helped in contacting local government officials in each research site, and asked them to invite one person from each of the 25 households that were involved in the 2002 survey to participate in our experiment. In each village, the chairman was charged with the duty of ensuring the participants arrived in time at the session. On average, 21 individuals participated in each village. We collected data from 166 participants in total, 87 participants in the North and 79 participants in the South.

The experimental sessions started at 8 a.m. and lasted about three hours including payment and the post-experimental demographic survey. At the beginning of each game, participants were given instructions in Vietnamese including a detailed description of the game, a set of examples, and record sheets with a series of questions to be answered for each game. Illiterate subjects (3\%) were given oral instructions by Vietnamese research assistants. Participants who had difficulty completing record sheets by themselves were also helped by assistants. On average, participants earned KVND 120 (about \$ 7) for the three games, roughly 3-4 days' wage for casual unskilled labor. They were paid in a separate room so that earnings could be kept private.

\subsection{Description of the pool of participants}

Table 1 gives some descriptive statistics by region. The characteristics in the first panel are those reported by the participants and those in the second panel were elicited during the experiment.

from those surveyed by Tanaka et al. (2010). We ran one session in each village to avoid contamination effects. 
Table 1. Descriptive statistics of participants by region

\begin{tabular}{|c|c|c|c|c|c|c|}
\hline & \multicolumn{2}{|c|}{ North } & \multicolumn{2}{|c|}{ South } & \multicolumn{2}{|c|}{ Total } \\
\hline & Mean & S.D. & Mean & S.D. & Mean & S.D. \\
\hline \multicolumn{7}{|c|}{ Characteristics reported by the participants } \\
\hline Age & 53 & 11.77 & $47 * * *$ & 9.94 & 50 & 11.30 \\
\hline Female & 0.57 & 0.50 & $0.32 * * *$ & 0.47 & 0.45 & 0.50 \\
\hline Years of education & 8.47 & 4.59 & $7.15 * *$ & 3.62 & 7.8 & 4.19 \\
\hline First job in agriculture & 0.70 & 0.46 & 0.62 & 0.49 & 0.66 & 0.47 \\
\hline Holding a second job & 0.44 & 0.50 & 0.38 & 0.49 & 0.41 & 0.49 \\
\hline \multicolumn{7}{|c|}{ Characteristics elicited in the experiment } \\
\hline Probability weighting $(\alpha)$ & 0.633 & 0.206 & 0.645 & 0.241 & 0.638 & 0.223 \\
\hline Risk aversion $(\sigma)$ & 0.553 & 0.275 & 0.569 & 0.274 & 0.561 & 0.274 \\
\hline Loss aversion $(\lambda)^{12}$ & 3.542 & 3.242 & $2.676^{* *}$ & 3.056 & 3.130 & 3.175 \\
\hline Time discounting rate $(r)$ & 0.005 & 0.014 & 0.003 & 0.012 & 0.004 & 0.013 \\
\hline Present bias $(\beta)$ & 0.610 & 0.610 & 0.560 & 0.560 & 0.586 & 0.161 \\
\hline Number of participants & \multicolumn{2}{|c|}{87} & \multicolumn{2}{|c|}{79} & \multicolumn{2}{|c|}{166} \\
\hline
\end{tabular}

Notes: a) S.D. for standard deviation. b)Mann-Whitney rank-sum tests comparing the sample from the North and the sample from the South. b) $* * *$ indicate significance at the $1 \%$ level and $* *$ at the $5 \%$ level.

According to Mann-Whitney tests in which each individual is an independent observation, the participants from the North are slightly older and more educated on average than those from the South and the share of females is higher. The proportions of participants holding an occupation in agriculture and having a secondary job are fairly balanced in the two regions. As for risk preferences, only the loss aversion parameter is significantly different: participants are more loss averse in the North than in the South. Time preferences do not differ significantly across regions. Note that the probability weighting $(\alpha)$ is significantly smaller than 1 and the loss aversion parameters $(\lambda)$ is significantly greater than 1 in both regions $(t$-tests, $p<0.001)$. This finding rejects the EU function and shows that the utility of participants is better described by an inverted S-shaped utility function (they overweight small probabilities and underweight large probabilities) and by loss aversion. The mean estimated values of $(\alpha, \sigma)$ are $(0.633,0.553)$ for the North and $(0.645,0.569)$ for the South. ${ }^{13}$ These values are close to those estimated by Tanaka $e t$

\footnotetext{
${ }^{12} \lambda$ is the midpoint of the lower and upper bounds of the switching point in questions of series 3 in game 1 and it takes different values when risk aversion $(\sigma)$ differs. Here, we used the values of $\lambda$ corresponding to $\sigma=1$. The level of significance of the comparison between North and South is not affected when taking other values of $\sigma$.

${ }^{13}$ OLS estimates of the curvature of the utility function against individual characteristics show that participants with
} 
al. (2010) for the North $(0.74,0.59)$ and the South $(0.74,0.63)$ of Vietnam, and to those found by Liu (2012) with the same method for farmers in China $(0.69,0.48)$. Our estimation of $\lambda$ is 3.542 in the North and 2.676 in the South (they were 2.25 in Tversky and Kahneman, 1992; 2.63 in Tanaka et al. (2010); 3.47 in Liu, 2012). ${ }^{14}$

Regarding time preferences, the mean values of the time discounting rate $(r)$ and of the present bias parameter $(\beta)$ are 0.005 and 0.610 , respectively, in the North and 0.003 and 0.560 , respectively, in the South. ${ }^{15}$ In Tanaka et al. (2010), the estimates for the full sample were 0.008 for $r$ and 0.644 for $\beta$, showing that our participants are somewhat more present biased than those in their study. In Brown et al. (2009), the estimates of $\beta$ are between 0.62 and 0.72 . In our estimates, $\beta$ is significantly different from 1 in both regions $(p<0.001)$, which tends to reject the exponential discounting model and to support the quasi-hyperbolic discounting model.

\section{RESULTS}

We now turn to analyzing the results from the trust game. We first show summary statistics indicating that the level of trust is relatively similar in both regions of Vietnam, but that both expectations about trustworthiness and the degree of trustworthiness differ across regions. Then, we explore the determinants of trust and trustworthiness by means of a regression analysis.

\subsection{Summary statistics}

Table 2 presents summary statistics by region. Trust is measured by the mean amount sent by the trusters. Trustworthiness is captured by the mean amount returned by the trustees conditional on each amount possibly sent by the truster, and the mean proportion returned for each possible tripled amount received. Finally, Table 2 mentions the percentage of trustees who return more than the tripled amount sent by the truster.

\footnotetext{
a higher income are more risk seeking ( $\sigma$ is lower) and, controlling for absolute income, those who have a higher relative income are more risk averse. In the North only, higher education is associated with a higher risk aversion. The regression of risk parameters against demographic variables is available upon request.

14 Regression results for loss aversion show that older participants are less loss averse but the relationship is U-shaped. Richer participants are more loss averse, while receiving international remittances reduces loss aversion.

${ }_{15}$ Regression results for discount rate and present bias conclude that females are less patient than males ( $r$ is higher)and participants who hold a second job are less present biased ( $\beta$ is higher). No relationship has been found between the discount rate or present bias and income.
} 
While Table 2 indicates the mean return expected by the trusters, Figure 1 displays the expectations of the trusters for each possible amount sent to the trustee, by region. It does not include the expectations of participants who send nothing since there are only 2 observations.

Table 2. Summary statistics on trust and trustworthiness, by region

\begin{tabular}{rllll}
\hline & \multicolumn{1}{c}{ All } & \multicolumn{1}{c}{ North } & \multicolumn{1}{c}{ South } & $p$-values \\
\hline Mean amount sent by trusters & $9.85(5.12)$ & $9.43(4.91)$ & $10.32(5.33)$ & 0.289 \\
\% trusters sending 0 & 1.20 & 1.15 & 1.27 & \\
$-\quad$ sending 5 & 37.35 & 39.08 & 35.44 & \\
$-\quad$ sending 10 & 37.35 & 41.38 & 32.91 & $0.539^{\mathrm{a}}$ \\
$-\quad$ sending 15 & 11.45 & 6.90 & 16.46 & \\
$-\quad$ sending 20 & 12.65 & 11.49 & 13.92 & \\
\hline Mean expected return & $16.69(10.99)$ & $14.05(8.63)$ & $19.61(12.52)$ & 0.004 \\
\hline Mean amount returned by trustees & & & \\
if truster sends 5 & $10.77(5.61)$ & $9.72(5.01)$ & $11.93(6.03)$ & 0.012 \\
if truster sends 10 & $16.46(8.42)$ & $14.06(5.65)$ & $19.10(10.06)$ & 0.001 \\
if truster sends 15 & $20.82(10.90)$ & $15.79(6.97)$ & $24.87(11.81)$ & $<0.001$ \\
if truster sends 20 & $25.54(12.86)$ & $20.98(9.46)$ & $30.57(14.23)$ & $<0.001$ \\
\hline Mean amount returned as \%of amount sent *3 & & & \\
if truster sends 5 & $71.83(37.42)$ & $64.83(33.41)$ & $79.54(40.21)$ & 0.012 \\
if truster sends 10 & $54.86(28.07)$ & $46.86(18.84)$ & $63.67(33.55)$ & 0.001 \\
if truster sends 15 & $46.26(24.22)$ & $35.10(15.48)$ & $55.27(26.26)$ & $<0.001$ \\
if truster sends 20 & $42.57(21.44)$ & $34.96(15.76)$ & $50.95(23.72)$ & $<0.001$ \\
Mean \% & $54.07(21.74)$ & $46.52(15.63)$ & $62.39(24.43)$ & $<0.001$ \\
\hline \% trustees returning more than amount received*3 & & \\
if truster sends 5 & 8.43 & 4.60 & 12.66 & 0.063 \\
if truster sends 10 & 3.61 & 0 & 7.59 & 0.009 \\
if truster sends 15 & 2.13 & 0 & 3.85 & 0.117 \\
if truster sends 20 & 0.60 & 0 & 1.26 & 0.294 \\
\hline
\end{tabular}

Notes: a) The samples include 87 observations for the North and 79 for the South. However, due to mistakes in recording data, 25 observations are missing for the return of trustees in case the truster has sent 15 (one village with 24 observations in the North and one observation in the South). b) Amounts are expressed in KVND. c) $p$-values are from two sample Mann-Whitney rank sum tests comparing the North and South samples. An exception is ${ }^{a}$ that corresponds to a two sample Kolmogorov-Smirnov test for equality of distributions for all possible amounts sent.

Regarding trust, Table 2 shows that the mean amount sent by the trusters is KVND 9.85, which represents $49.25 \%$ of the initial endowment. Trusters transfer $47.15 \%$ of their endowment in the North and $51.60 \%$ in the South but the difference is not statistically significant. A Kolmogorov-Smirnov test also concludes that the distribution of transfers does not differ across regions. Only two participants - one in each region- played the Nash equilibrium strategy, i.e. 
sent 0 . Overall, the degree of trust in both regions is comparable with other studies. ${ }^{16}$

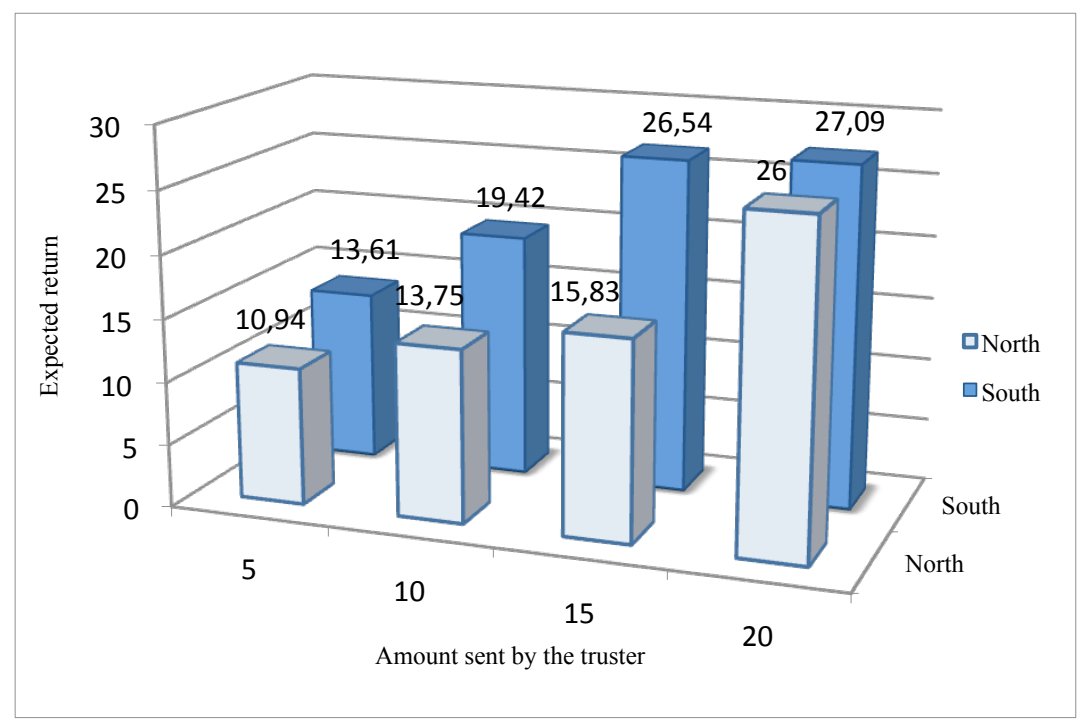

Figure 1. Trusters' expectations regarding the return from trustees, by region and amount sent

Trust is likely to be motivated by the expectation of reciprocity. Indeed, Figure 1 shows that the more they transfer, the more trusters expect to receive in return. Interestingly, trusters in the North expect less reciprocity from their counterpart than trusters in the South, except those who send all their endowment. In particular, the trusters in the North who send 15 expect that trustees will only return 15.83 on average. Overall, the mean expected return is 14.04 in the North and 19.61 in the South $(p=0.004)$. These results indicate that $i)$ if trust is driven by the expectation of reciprocity, it also responds to other motivations such as unconditional other-regarding preferences; $i$ ) individuals express the same level of trust in the North and in the South although the formers are less confident on the return of their transfer.

Regarding trustworthiness, the Nash equilibrium is almost never played (one observation when

\footnotetext{
${ }^{16}$ In a meta-analysis of 84 studies of the trust game, Johnson and Mislin (2008) show that, on average, trusters send $50.88 \%$ of their endowment although variations across studies are large. We are aware that the level of stakes matters and that higher stakes tend to slightly reduce trust. In our case, KVND 20 represent between half-a-day's and a full day's wage. For a stake of a full day's wage in Russia, Bahri and Wilson (2004) found that $62 \%$ of the subjects send at least $50 \%$ of their endowment. We found $61.45 \%$ in our sample. Studying trust with a public goods game, Carpenter et al. (2004) found that Vietnamese were more trusting than Thais, but the result may be driven by the possibility to sanction deviations from the norm. Comparing American students and recent immigrants from Vietnam, Parks and Vu (1994) found that Vietnamese were more cooperative in public goods games.
} 
the transfer is 5 or 10 and three observations when it is 15). Trustees return on average 54.07\% of the tripled amount received (S.D. $=21.74)$. This percentage is relatively high compared with previous studies, which suggests that our participants in general exhibit a relatively high mutual benefit orientation. ${ }^{17}$ The mean return rate is significantly higher in the South $(62.39 \%)$ than in the North $(46.52 \%)$. The higher trustworthiness in the South is observed for any amount sent by the trusters. However, simple comparisons should be taken with care since the two samples present some differences in terms of participants' individual characteristics.

The absolute amount returned increases in the amount potentially received, confirming that trustees are willing to return the trust expressed by the trusters. However, the amount returned represents a decreasing percentage of the tripled amount received as this amount increases (for example, it represents $71.83 \%$ of the amount received when the transfer is 5 , but $42.57 \%$ when it is 20). This suggests that most people do not try to equalize payoffs (equalization would require that the trustee sends back two thirds of the tripled amount received). In addition, Table 2 indicates that a small fraction of the participants return more than the total amount received when transfers are low. By doing so, they reduce their payoff and increase inequality at the benefit of the other player. This suggests that a low transfer is not necessarily interpreted as a lack of trust and that trustworthiness stem also from unconditional other-regarding preferences like kindness. This interpretation is consistent with Cox (2004) and Ashraf et al. (2006).

To investigate further the determinants of behavior, we proceed now to an econometric analysis.

\subsection{Econometric analysis}

\section{The determinants of trust}

To identify the determinants of trust, we estimate several models whose results are displayed in Table 3. The dependent variable is the amount sent by the trusters. Model (1) presents a simple Ordinary Least Square model. Since the trust variable is censored both on the left (when the participant sends nothing) and on the right (when the full endowment is sent), we also estimate a Tobit model (model (2)). In these first two models, we include the participant's total income

\footnotetext{
${ }^{17}$ The meta-analysis of Johnson and Mislin (2011) based on 75 studies finds a mean rate of return of 36.51\%, which simply compensates -on average- the trusters.
} 
among the independent variables. However, total income may be endogenous as it may influence trust but it may also be determined by the ability to trust others. For that reason coupling with potential measurement errors in income reporting, we use instrumental variables for the income variable. Specifically, we use rainfalls at the time and the precise location of the survey as an exogenous instrument for the income. Indeed, weather is likely to influence income, as most participants hold jobs related to agriculture, but it has no reason to correlate with trust. We estimate an Instrumental Variable Two-Stage Least Square regression (IV-2SLS) for trust. In the first stage, we estimate the correlation between income and rainfalls, which is significant at the one percent level (model (3)). In the second stage, we estimate the determinants of trust after controlling for the endogeneity problem of income instrumented by rainfalls (model (4)). Finally, we estimate a two-stage Tobit model with the same instrumented income (model (5)).

In these regressions, the independent variables include the expectation of the individual regarding the amount returned by the trustee since we expect that trust is partly motivated by the expectation of reciprocity. The models also account for a number of individual characteristics. These characteristics include the estimated parameters for risk attitudes (probability weighting, $\alpha$, risk aversion, $\sigma$, and loss aversion, $\lambda$ ) and for time preferences (time discounting rate, $r$, and present bias, $\beta$ ). ${ }^{18}$ We control for demographic variables (age and age squared, gender, and years of education), for the occupational status (first job being in agriculture, holding a second job) and for both absolute income (with or without its instrument) and relative income. ${ }^{19}$ The independent variables include the amount of international and domestic remittances received by the household as indicated by the VHLSS 2002. We use remittances as a proxy for the

\footnotetext{
18 As indicated in footnote $12, \lambda$ is the midpoint of the lower bound and upper bound of the switching point in questions of series 3 in game 1 and it takes different values when risk aversion $(\sigma)$ differs. In all the regression analysis reported in this paper, we use the values of $\lambda$ corresponding to $\sigma=1$. We also estimated the models with a value of $\lambda$ given by $\sigma=0.2$ and by $\sigma=0.6$ (not reported here but available upon request). The level of significance of $\lambda$ remains the same when using the other values of $\sigma$, except that loss aversion becomes significant at the $10 \%$ level in the OLS regression reported in Table A5 in Appendix 4 instead of being significant at the $11 \%$ level.

19 Financial data come from the VHLSS 2002. Total income has been reconstituted by adding all the sources of income of the households as detailed in the survey. Since the experiment was already more than three hours long, it would have been difficult to collect truthful additional information on the various financial resources at the end of the sessions. Relative income measures the household's relative status in the village. It is calculated as the proportion of each household's income in the mean income of the participants from the same village. Alternatively, we have also calculated the relative income as the difference between the household income and the mean income in the village divided by the standard deviation of income in the village. The results are similar.
} 
experience of receiving gifts. We control for the number of acquaintances in the session since individuals may be more trustful with their anonymous counterpart if it is more likely that they know him personally (see the importance of the target in trust games in McEvily et al., 2012, or of social distance in Song et al., 2012). Finally, we include a dummy variable for the sessions conducted in the South. Table A5 in Appendix 4 complements this analysis by reporting estimates of the same models as in Table 3, with the expected return as the dependent variable. Table 3 indicates that all the models give very similar outcomes. First, trust is highly significantly influenced by the expected return from the trustee. This suggests that trusting is partly calculative: the more people trust others, the more they expect to receive in return. ${ }^{20}$

The second important result is that neither risk preferences nor time preferences have significant influence on the level of trust, although trust involves risk in the sense that the first player may have to endure losses if the second player defects. Neither the probability weighting function parameter nor the degree of risk aversion influence trust significantly. This result is consistent with the findings of Eckel and Wilson (2004), Ashraf et al. (2006), Houser et al. (2010), and McEvily et al. (2012). These parameters do not correlate either with the expectations of return from trustees (see Table A5).A possible interpretation is that either trusters do not interpret the trust game as a situation involving risk or individuals' risk preferences towards lottery choices differ from the attitude towards strategic uncertainty. In contrast, we find loss aversion indirectly correlate with trust as it negatively correlates with the expectations of return (see Table A5). Regarding time preferences, discounting rate and present bias do not have direct or indirect effect on trusting decisions.

${ }^{20}$ Of course, we must remain cautious with this interpretation as we cannot rule out some self-justification since belief elicitation was not incentivized. 
Table 3.Determinants of trust

\begin{tabular}{|c|c|c|c|c|c|}
\hline & OLS (1) & Tobit (2) & OLS (3) & IV-2SLS (4) & IV-Tobit (5) \\
\hline Dependant variable & Trust & Trust & Income & Trust & Trust \\
\hline $\begin{array}{l}\text { Expectation of return } \\
\text { from player } 2\end{array}$ & $\begin{array}{l}0.228 * * * \\
(0.042)\end{array}$ & $\begin{array}{c}0.268 * * * \\
(0.051)\end{array}$ & $\begin{array}{l}-0.081 \\
(0.093)\end{array}$ & $\begin{array}{c}0.227 * * * \\
(0.040)\end{array}$ & $\begin{array}{l}0.267 * * * \\
(0.051)\end{array}$ \\
\hline South $(=1)$ & $\begin{array}{l}-1.205 \\
(0.958)\end{array}$ & $\begin{array}{l}-1.546 \\
(1.084)\end{array}$ & $\begin{array}{l}20.948 * * * \\
(5.132)\end{array}$ & $\begin{array}{l}-1.508 \\
(0.965)\end{array}$ & $\begin{array}{l}-2.016^{*} \\
(1.194)\end{array}$ \\
\hline $\begin{array}{l}\text { Probability weighting } \\
(\alpha)\end{array}$ & $\begin{array}{l}-0.663 \\
(1.696)\end{array}$ & $\begin{array}{l}-0.439 \\
(1.861)\end{array}$ & $\begin{array}{l}-2.030 \\
(5.586)\end{array}$ & $\begin{array}{l}-0.693 \\
(1.621)\end{array}$ & $\begin{array}{l}-0.449 \\
(1.929)\end{array}$ \\
\hline $\begin{array}{l}\text { Risk aversion } \\
(\sigma)\end{array}$ & $\begin{array}{l}-1.018 \\
(1.572)\end{array}$ & $\begin{array}{l}-1.607 \\
(1.737)\end{array}$ & $\begin{array}{l}-4.808 \\
(4.301)\end{array}$ & $\begin{array}{l}-1.163 \\
(1.535)\end{array}$ & $\begin{array}{l}-1.838 \\
(1.829)\end{array}$ \\
\hline $\begin{array}{l}\text { Loss aversion } \\
(\lambda)\end{array}$ & $\begin{array}{l}-0.092 \\
(0.122)\end{array}$ & $\begin{array}{l}-0.117 \\
(0.136)\end{array}$ & $\begin{array}{c}0.432 \\
(0.396)\end{array}$ & $\begin{array}{l}-0.066 \\
(0.121)\end{array}$ & $\begin{array}{l}-0.077 \\
(0.144)\end{array}$ \\
\hline $\begin{array}{l}\text { Time discounting rate } \\
\text { (r) }\end{array}$ & $\begin{array}{c}37.954 \\
(27.193)\end{array}$ & $\begin{array}{c}42.875 \\
(29.415)\end{array}$ & $\begin{array}{c}-8.688 \\
(87.518)\end{array}$ & $\begin{array}{c}35.747 \\
(24.965)\end{array}$ & $\begin{array}{c}39.886 \\
(28.718)\end{array}$ \\
\hline $\begin{array}{l}\text { Present bias } \\
(\beta)\end{array}$ & $\begin{array}{l}-0.349 \\
(3.183)\end{array}$ & $\begin{array}{l}-0.286 \\
(3.610)\end{array}$ & $\begin{array}{l}10.339 \\
(9.209)\end{array}$ & $\begin{array}{c}0.003 \\
(3.027)\end{array}$ & $\begin{array}{c}0.255 \\
(3.674)\end{array}$ \\
\hline $\begin{array}{l}\text { Number of } \\
\text { acquaintances }\end{array}$ & $\begin{array}{c}0.046 \\
(0.074)\end{array}$ & $\begin{array}{c}0.043 \\
(0.082)\end{array}$ & $\begin{array}{l}-0.818 * * \\
(0.349)\end{array}$ & $\begin{array}{c}0.023 \\
(0.073)\end{array}$ & $\begin{array}{c}0.007 \\
(0.091)\end{array}$ \\
\hline Age & $\begin{array}{l}0.307^{*} \\
(0.158)\end{array}$ & $\begin{array}{l}0.339 * * \\
(0.172)\end{array}$ & $\begin{array}{c}0.783 \\
(0.590)\end{array}$ & $\begin{array}{l}0.318 * * \\
(0.153)\end{array}$ & $\begin{array}{l}0.356 * * \\
(0.180)\end{array}$ \\
\hline Age squared & $\begin{array}{c}-0.004 * * \\
(0.002)\end{array}$ & $\begin{array}{c}-0.004 * * \\
(0.002)\end{array}$ & $\begin{array}{l}-0.007 \\
(0.006)\end{array}$ & $\begin{array}{c}-0.004 * * \\
(0.002)\end{array}$ & $\begin{array}{c}-0.004 * * \\
(0.002)\end{array}$ \\
\hline $\operatorname{Female}(=1)$ & $\begin{array}{l}-0.330 \\
(0.785)\end{array}$ & $\begin{array}{l}-0.484 \\
(0.857)\end{array}$ & $\begin{array}{l}-1.732 \\
(3.127)\end{array}$ & $\begin{array}{l}-0.434 \\
(0.785)\end{array}$ & $\begin{array}{l}-0.638 \\
(0.926)\end{array}$ \\
\hline Years of education & $\begin{array}{c}-0.151 * * \\
(0.071)\end{array}$ & $\begin{array}{l}-0.151 * * \\
(0.076)\end{array}$ & $\begin{array}{c}0.372 \\
(0.261)\end{array}$ & $\begin{array}{l}-0.151 * * \\
(0.067)\end{array}$ & $\begin{array}{l}-0.153 * \\
(0.079)\end{array}$ \\
\hline $\begin{array}{l}\text { First job being in } \\
\text { agriculture }(=1)\end{array}$ & $\begin{array}{l}-1.333 \\
(0.831)\end{array}$ & $\begin{array}{l}-1.555^{*} \\
(0.897)\end{array}$ & $\begin{array}{l}-5.799 \\
(4.278)\end{array}$ & $\begin{array}{l}-1.384 * \\
(0.802)\end{array}$ & $\begin{array}{l}-1.651 * \\
(0.950)\end{array}$ \\
\hline $\begin{array}{l}\text { Having a second } \\
\text { job }(=1)\end{array}$ & $\begin{array}{l}1.887 * * \\
(0.775)\end{array}$ & $\begin{array}{l}2.158 * * \\
(0.847)\end{array}$ & $\begin{array}{c}0.771 \\
(2.622)\end{array}$ & $\begin{array}{l}2.002 * * * \\
(0.720)\end{array}$ & $\begin{array}{c}2.337 * * * \\
(0.853)\end{array}$ \\
\hline Total income $(/ 1000)$ & $\begin{array}{c}0.027 \\
(0.021)\end{array}$ & $\begin{array}{c}0.028 \\
(0.023)\end{array}$ & - & $\begin{array}{l}-0.007 \\
(0.048)\end{array}$ & $\begin{array}{l}-0.023 \\
(0.057)\end{array}$ \\
\hline Relative income & $\begin{array}{l}-0.361 \\
(0.900)\end{array}$ & $\begin{array}{l}-0.265 \\
(1.003)\end{array}$ & $\begin{array}{c}41.424 * * * \\
(2.895)\end{array}$ & $\begin{array}{c}1.026 \\
(2.068)\end{array}$ & $\begin{array}{c}1.839 \\
(2.503)\end{array}$ \\
\hline $\begin{array}{l}\text { Amount of internat. } \\
\text { remittances }(/ 1000)\end{array}$ & $\begin{array}{l}0.130 * \\
(0.070)\end{array}$ & $\begin{array}{l}0.163 * \\
(0.088)\end{array}$ & $\begin{array}{l}-0.071 \\
(0.196)\end{array}$ & $\begin{array}{l}0.132 * * \\
(0.063)\end{array}$ & $\begin{array}{l}0.165 * * \\
(0.083)\end{array}$ \\
\hline $\begin{array}{l}\text { Amount of domestic } \\
\text { remittances }(/ 1000)\end{array}$ & $\begin{array}{l}-0.183 \\
(0.178)\end{array}$ & $\begin{array}{l}-0.198 \\
(0.186)\end{array}$ & $\begin{array}{l}-0.547 \\
(0.738)\end{array}$ & $\begin{array}{l}-0.178 \\
(0.166)\end{array}$ & $\begin{array}{l}-0.190 \\
(0.187)\end{array}$ \\
\hline Average rainfalls & - & - & $\begin{array}{c}18.220 * * * \\
(3.059)\end{array}$ & - & - \\
\hline Number of observ. & 156 & 156 & 156 & 156 & 156 \\
\hline left / right censored & - & $2 / 21$ & - & - & $2 / 21$ \\
\hline C-Donald Wald F statistic & - & - & 37.268 & - & - \\
\hline Wald test of exogeneity & - & - & - & 0.890 & 0.330 \\
\hline $\mathrm{R}^{2}$ & 0.348 & 0.073 & 0.893 & 0.338 & - \\
\hline
\end{tabular}

Notes: a) Theseregressions include only 156 observations due to a lack of information regarding income and remittances for 10participants in the 2002 household survey data. b) Standard errors are in parentheses. c) $* * *$ indicate significance at the $1 \%$ level, ** at the $5 \%$ level and * at the $10 \%$ level. 
The third interesting result is that having received higher international remittances in the past is directly associated with a higher level of trust although it has a negative impact on the expectation of return. The amount of international remittances is high relative to regular income (see Table A1 in Appendix 2); but since we control for the total income including remittances ${ }^{21}$, the international remittances variable should not capture a pure wealth effect. In the real world, international remittances are frequently sent to the family in return for initial help given to the migrant. Our findings suggest that the trusters who send more are more likely to have faced in their life a similar situation of trusting family members who migrated. These individuals may expect less return from strangers -like in our game- than from their migrant family member.

A few other individual characteristics matter. Table 3 shows an inverted U-shaped relationship between age and trust that is not influenced by differences in expectations related to age. This result is consistent with previous findings (see Carpenter et al., 2004; Sutter and Kocher, 2007;Bellemare and Kröger, 2007). Interestingly, in alternative specifications with separate regressions by region in which age is entered linearly (available upon request), we find that age has a significant negative impact on trust in the North, but not in the South (OLS, North: coeff. $=-0.104, p=0.020$; South: coeff. $=0.013, p=0.817$ ). This suggests that people who had a longer exposure to a socialist regime may be less trustful. Table A5 also shows that participants from the North hold significantly lower expectations of return than participants in the South.

Table 3 indicates that more educated participants are less trustful (as in Schechter, 2007, and McEvily et al., 2012) although higher education is not correlated with lower expectations. Controlling for total and relative income, participants whose first occupation is in agriculture-which probably indicates less stable resources- are less trustful while holding a second job greatly increases one's level of trust. However, income has no direct impact on trust, in contrast with previous findings (Bellemare and Kröger, 2007). Finally, we find no effect of gender on trust (similarly to Croson and Buchan, 1999; Ashraf et al. 2006; Cox and Deck, 2006). In their survey on gender effects in 20 studies of the trust game, Croson and Gneezy (2009) find

21 We have also estimated the models with income excluding remittances; the estimated results remain the same. 
that gender is reported to influence trust in 12 of them.

We summarize our main results on trust in our experiment as follows:

Result 1: Trust is partly driven by the expectation of return from the trustee.

Result 2: Probability weighting, risk aversion, time discounting and present bias do not influence trust. In contrast, loss aversion impacts trust indirectly through its negative impact on the expected return of trust.

Result 3: Trust is positively correlated with past experience of receiving international remittances.

Result 4: Older individuals in the North are significantly less trustful, possibly because of a longer exposure to a collectivist culture. Institutional differences also influence expectations on trustworthiness, with individuals in the North having lower expectations of return.

\section{The determinants of trustworthiness}

To analyze trustworthiness, we have estimated several models in which the dependent variable is the proportion of potential total amount received (three times the potential amount sent by the truster) that is returned by the trustee. Table 4 displays the results of the main regressions. Since each individual is observed four times (when player 1 sends 5, 10, 15 and 20) ${ }^{2223}$, robust standard errors are clustered at the individual level. Model (1) is an OLS regression. As with the trust regressions, we estimate an IV-2SLS model for trustworthiness in which rainfalls instrument total income (see model (3) for the first-stage income regression and model (4) for the second stage regression with the instrumental variable). Models (2) and (5) are Tobit models without and with instrumental variable, respectively, to account for left censored observations at 0 and right censored observations at 1 or more (when trustees return at least or more than the tripled amount potentially received). ${ }^{24} 25$ In all regressions, the set of independent variables is the same as in Table 3, except that we include a variable indicating the amount potentially sent by the

\footnotetext{
${ }^{22}$ For the sake of comparability with other studies, all observations with transfers equal to 0 are discarded from this analysis because we are interested in studying reciprocity.

23 Except 23 participants who were observed only three times because of a mistake in registering the amount returned in one village when receiving KVND 15. Note that we have reestimated the models reported in Table 3 with only 133 participants. The results are unaffected.

${ }^{24}$ Using a General Least Square method of estimation with random errors and robust standard errors or a Tobit model with random errors gives similar results (available upon request).

25 Alternatively, given the dependent variable takes a proportional value (between 0 and 1), we can use the generalized least squared (GLS) with binominal data method.
} 
truster (that takes values $5,10,15$ or 20 ) and we exclude the expected return that was included in Table 3. This variable is an indicator of reciprocity.

Table 4. The determinants of trustworthiness

\begin{tabular}{|c|c|c|c|c|c|}
\hline & OLS (1) & Tobit (2) & OLS (3) & IV-2SLS (4) & IV-Tobit (5) \\
\hline Dependant variable & $\begin{array}{c}\text { Proportion } \\
\text { returned }\end{array}$ & $\begin{array}{c}\text { Proportion } \\
\text { returned }\end{array}$ & Income & $\begin{array}{c}\text { Proportion } \\
\text { returned }\end{array}$ & $\begin{array}{c}\text { Proportion } \\
\text { returned }\end{array}$ \\
\hline $\begin{array}{l}\text { Conditional } \\
\text { amount sent }\end{array}$ & $\begin{array}{c}-0.020 * * * \\
(0.002)\end{array}$ & $\begin{array}{c}-0.019 * * * \\
(0.002)\end{array}$ & $\begin{array}{c}-0.032 * * * \\
(0.008)\end{array}$ & $\begin{array}{c}-0.020 * * * \\
(0.002)\end{array}$ & $\begin{array}{c}-0.019 * * * \\
(0.002)\end{array}$ \\
\hline South $(=1)$ & $\begin{array}{c}0.143 * * * \\
(0.034)\end{array}$ & $\begin{array}{c}0.130 * * * \\
(0.032)\end{array}$ & $\begin{array}{c}18.074 * * * \\
(4.561)\end{array}$ & $\begin{array}{c}0.149 * * * \\
(0.035)\end{array}$ & $\begin{array}{c}0.143 * * * \\
(0.034)\end{array}$ \\
\hline $\begin{array}{l}\text { Probability } \\
\text { weighting }(\alpha)\end{array}$ & $\begin{array}{l}-0.075 \\
(0.068)\end{array}$ & $\begin{array}{l}-0.105 \# \\
(0.065)\end{array}$ & $\begin{array}{l}-2.221 \\
(5.228)\end{array}$ & $\begin{array}{l}-0.074 \\
(0.067)\end{array}$ & $\begin{array}{l}-0.104 \# \\
(0.065)\end{array}$ \\
\hline $\begin{array}{l}\text { Risk aversion } \\
(\sigma)\end{array}$ & $\begin{array}{l}0.150 * * \\
(0.064)\end{array}$ & $\begin{array}{c}0.168 * * * \\
(0.060)\end{array}$ & $\begin{array}{l}-4.102 \\
(3.744)\end{array}$ & $\begin{array}{c}0.153 * * \\
(0.065)\end{array}$ & $\begin{array}{l}0.173 * * * \\
(0.061)\end{array}$ \\
\hline $\begin{array}{l}\text { Loss aversion } \\
(\lambda)\end{array}$ & $\begin{array}{l}-0.006 \\
(0.005)\end{array}$ & $\begin{array}{l}-0.005 \\
(0.005)\end{array}$ & $\begin{array}{c}0.313 \\
(0.363)\end{array}$ & $\begin{array}{l}-0.006 \\
(0.005)\end{array}$ & $\begin{array}{l}-0.006 \\
(0.005)\end{array}$ \\
\hline $\begin{array}{l}\text { Time discounting } \\
\text { rate }(\mathrm{r})\end{array}$ & $\begin{array}{l}-1.387 \\
(1.370)\end{array}$ & $\begin{array}{l}-1.191 \\
(1.321)\end{array}$ & $\begin{array}{c}7.406 \\
(78.623)\end{array}$ & $\begin{array}{l}-1.351 \\
(1.368)\end{array}$ & $\begin{array}{l}-1.117 \\
(1.359)\end{array}$ \\
\hline $\begin{array}{l}\text { Present bias } \\
(\beta)\end{array}$ & $\begin{array}{l}0.269 * * \\
(0.120)\end{array}$ & $\begin{array}{l}0.282 * * \\
(0.113)\end{array}$ & $\begin{array}{c}6.215 \\
(8.025)\end{array}$ & $\begin{array}{l}0.265 * * \\
(0.121)\end{array}$ & $\begin{array}{c}0.272 * * \\
(0.118)\end{array}$ \\
\hline $\begin{array}{l}\text { Number of } \\
\text { acquaintances }\end{array}$ & $\begin{array}{c}0.001 \\
(0.003)\end{array}$ & $\begin{array}{l}<0.001 \\
(0.002)\end{array}$ & $\begin{array}{c}-0.934 * * * \\
(0.343)\end{array}$ & $\begin{array}{c}0.001 \\
(0.003)\end{array}$ & $\begin{array}{c}0.002 \\
(0.003)\end{array}$ \\
\hline Age & $\begin{array}{l}-0.001 \\
(0.007)\end{array}$ & $\begin{array}{l}<0.001 \\
(0.007)\end{array}$ & $\begin{array}{c}0.703 \\
(0.531)\end{array}$ & $\begin{array}{l}-0.001 \\
(0.007)\end{array}$ & $\begin{array}{l}<0.001 \\
(0.007)\end{array}$ \\
\hline Age squared & $\begin{array}{l}<0.001 \\
(<0.001)\end{array}$ & $\begin{array}{l}<0.001 \\
(<0.001)\end{array}$ & $\begin{array}{l}-0.007 \\
(0.005)\end{array}$ & $\begin{array}{l}<0.001 \\
(<0.001)\end{array}$ & $\begin{array}{l}<-0.001 \\
(<0.001)\end{array}$ \\
\hline $\operatorname{Female}(=1)$ & $\begin{array}{c}-0.115 * * * \\
(0.028)\end{array}$ & $\begin{array}{c}-0.111 * * * \\
(0.028)\end{array}$ & $\begin{array}{l}-1.265 \\
(2.864)\end{array}$ & $\begin{array}{c}-0.113^{* * * *} \\
(0.029)\end{array}$ & $\begin{array}{c}-0.107 * * * \\
(0.029)\end{array}$ \\
\hline Years of education & $\begin{array}{c}-0.010 * * * \\
(0.003)\end{array}$ & $\begin{array}{c}-0.010 * * * \\
(0.003)\end{array}$ & $\begin{array}{c}0.335 \\
(0.233)\end{array}$ & $\begin{array}{c}-0.010 * * * \\
(0.003)\end{array}$ & $\begin{array}{c}-0.010 * * * \\
(0.003)\end{array}$ \\
\hline $\begin{array}{l}\text { First job being in } \\
\text { agriculture }(=1)\end{array}$ & $\begin{array}{l}-0.039 \\
(0.036)\end{array}$ & $\begin{array}{l}-0.048 \\
(0.035)\end{array}$ & $\begin{array}{l}-4.884 \\
(3.971)\end{array}$ & $\begin{array}{l}-0.039 \\
(0.035)\end{array}$ & $\begin{array}{l}-0.047 \\
(0.036)\end{array}$ \\
\hline $\begin{array}{l}\text { Having a second } \\
\text { job }(=1)\end{array}$ & $\begin{array}{c}0.014 \\
(0.034)\end{array}$ & $\begin{array}{c}0.012 \\
(0.031)\end{array}$ & $\begin{array}{c}0.620 \\
(2.200)\end{array}$ & $\begin{array}{c}0.011 \\
(0.032)\end{array}$ & $\begin{array}{c}0.007 \\
(0.031)\end{array}$ \\
\hline $\begin{array}{l}\text { Total income } \\
(/ 1000)\end{array}$ & $\begin{array}{l}<-0.001 \\
(0.001)\end{array}$ & $\begin{array}{l}<-0.001 \\
(0.001)\end{array}$ & - & $\begin{array}{l}<0.001 \\
(0.002)\end{array}$ & $\begin{array}{c}0.001 \\
(0.002)\end{array}$ \\
\hline Relative income & $\begin{array}{c}0.041 \\
(0.038)\end{array}$ & $\begin{array}{c}0.043 \\
(0.039)\end{array}$ & $\begin{array}{l}40.178 * * * \\
(2.776)\end{array}$ & $\begin{array}{l}0.008 \\
(0.091)\end{array}$ & $\begin{array}{l}-0.025 \\
(0.087)\end{array}$ \\
\hline $\begin{array}{l}\text { Amount of internat. } \\
\text { remittances }(/ 1000)\end{array}$ & $\begin{array}{c}-0.004 * * * \\
(0.001)\end{array}$ & $\begin{array}{l}-0.004 * * * \\
(0.001)\end{array}$ & $\begin{array}{l}-0.019 \\
(0.166)\end{array}$ & $\begin{array}{c}-0.004 * * * \\
(0.001)\end{array}$ & $\begin{array}{c}-0.004 * * * \\
(0.001)\end{array}$ \\
\hline $\begin{array}{l}\text { Amount of domestic } \\
\text { remittances }(/ 1000)\end{array}$ & $\begin{array}{l}0.021 * * * \\
(0.006)\end{array}$ & $\begin{array}{l}0.019 * * * \\
(0.007)\end{array}$ & $\begin{array}{l}-0.375 \\
(0.659)\end{array}$ & $\begin{array}{l}0.020 * * * \\
(0.006)\end{array}$ & $\begin{array}{l}0.018 * * * \\
(0.007)\end{array}$ \\
\hline Average rainfalls & - & - & $\begin{array}{c}16.180 * * * \\
(2.781)\end{array}$ & - & - \\
\hline Number of observat. & 595 & 595 & 595 & 595 & 595 \\
\hline Left/right censored & - & $4 / 76$ & - & - & $4 / 76$ \\
\hline \multirow{2}{*}{\multicolumn{2}{|c|}{$\begin{array}{l}\text { Cragg-Donald Wald F statistic - } \\
\text { Wald test of exogeneity - }\end{array}$}} & - & 137.968 & - & - \\
\hline & & - & - & 0.67 & 0.386 \\
\hline
\end{tabular}


R2/ Pseudo R2

0.300

0.594

0.897

0.299

Notes: a) The five regressions have been conducted with robust standard errors, in parentheses, and clustering at the individual level. b) $* * *$ indicate significance at the $1 \%$ level, $* *$ at the $5 \%$ level and $\#$ at the $11 \%$ level.

If the absolute amount returned to the trusters increases in the level of trust ${ }^{26}$ Table 4 shows that the opposite holds for the proportion returned. This puzzling relationship contrasts notably with Ashraf et al. (2006) but is consistent with Schechter (2007); Barr (2003) found no relationship. Here, trustees are reciprocal in absolute terms but not in relative terms as they are fair with the trusters who do not send much and less generous with trusters who sent more. The fact that players do not sanction a low transfer reveals the presence of other motives than reciprocity in the amount returned and than unconditional other-regarding preferences (Cox, 2004). Trustees seem to interpret a low transfer not as a signal of low trust, but perhaps as a signal of more pressing monetary needs leading a truster not to take the risk of transferring money.

We did not expect to find a relationship between trustworthiness and risk preferences since the return decision does not involve any risk. In fact, Table 4 indicates that in all the models trustworthiness increases significantly in the concavity of the utility function $(\sigma)$. More risk averse players are more trustworthy. Eckel and Wilson (2004) have also arrived at the same finding. A possible interpretation is that although our game setting is one-shot and anonymous, individuals associate the return decision in the game with the fact that in real life, they feel committed to reciprocate positive actions from others, otherwise they risk damaging their reputation in the community. Individuals who are more anxious of their reputation alteration due to breaking the norm may be trustworthier. Moreover, the coefficient associated with probability weighting $\alpha$ is marginally significant in the Tobit regressions ( $p=0.104$ in model (2) and 0.111 in model (5)). Its sign is negative suggesting individuals who overweight small probabilities and underweight large probabilities are more likely to be less trustworthy. In contrast, trustworthiness is not related to loss aversion.

Table 4 shows that while time discounting does not influence trustworthiness significantly, present biased preferences do - less present biased trustees return more. In the real life, not being

\footnotetext{
${ }^{26}$ This is shown by similar models in which the dependent variable is the amount returned instead of the proportion
} returned. These regressions are available upon request. 
kind with someone who has been kind to you may generate a short run benefit but it may affect your reputation as being selfish, which in turn may deteriorate the future interactions with other villagers (long run cost). Given the timing gap in the realized cost and benefit of trustworthiness, present biased may play a role. More time consistent people focus more on the long run, and may be more willing to forego an immediate benefit to improve their long run position. Patience is a characteristic that may increase trustworthiness in general.

Remittances are highly significantly correlated with trustworthiness, negatively when they are international, positively when they are domestic. In the experiment, the beneficiaries of higher international remittances are more trustful but less trustworthy than the other participants (and they also expect significantly lower returns when they play as trusters). In real life, they are not expected to reciprocate to the senders of international remittances. So, the lower trustworthiness among international remittance receivers may reflect their "receivers" role in reality and lead to less reciprocation when sent a gift. The logic and amounts of domestic remittances are completely different (see Table A1 in Appendix 2). Using the Vietnam Migration Survey 2004, Niimit et al. (2008) highlight that domestic remittances play a co-insurance role within the family and among neighbors to face uncertainty. Not reciprocating a gift when one has enough resources to do it may be a norm-breaking behavior. The observation that the domestic remittance receivers return a higher proportion in the game than the other participants may reflect a learned experience of the norm of mutual help in real life.

Table 4 also indicates that trustees in the South of Vietnam are returning a significantly higher proportion of the amount received in the game than trustees in the North. This does not express a difference in reciprocity, however, since when we run separate regressions by region, the coefficient associated with the amount sent by the truster is very close $(-0.021$ in the North and -0.019 in the South). The differentiated role of other social preferences may be due to the different historical institutional settings in the two regions. The lower trustworthiness in the North may result from a longer exposure to a collectivist organization while a longer exposure to market economy in the South may have developed a better knowledge of what shared norms of 
fairness are. ${ }^{27}$ Overall, our analysis shows that both the expectations of return and trustworthiness differ across regions. This is in line with the meta-analysis of Johnson and Mislin (2011) showing that the effect of cultural variables is much stronger on trustworthiness than on trust. As a result of these differences, we find that earnings from the trust game are significantly higher in the South than in the North ( $t$-test, two-tailed: $p=0.001)$.

Finally, Table 4 indicates that more educated individuals exhibit lower trustworthiness than less educated individuals (similar to Bellemare and Kröger, 2007). Women are significantly less trustworthy when compared to men (also like in Bellemare and Kröger, 2007). In their survey on gender effects in 20 studies of the trust game, Croson and Gneezy (2009) report that in six of the eight studies that find gender differences in trustworthiness, females are trustworthier than males. We find the opposite. But when we decompose our regressions by region (available upon request), the negative effect of gender is only significant in the North. ${ }^{28}$ Age does not significantly influence trustworthiness (even when we interact age and region), which is in contrast with studies conducted in Europe in which older people are trustworthier than younger ones (Sutter and Kocher, 2007; Bellemare and Kröger, 2007). Absolute and relative incomes do not affect the proportion returned to the trusters (similar to Bellemare and Kröger, 2007). The number of acquaintances has no effect.

Our main findings regarding trustworthiness can be summarized as follows:

Result 5: Trustees are reciprocal in absolute terms but not in relative terms. In relative terms, they are more fair with trusters who send less than with those who send more, as if lower transfers were interpreted not as motivated by lower trust but by higher risk aversion perhaps due to poverty and more pressing economic needs.

Result 6: More risk averse and less present biased trustees are trustworthier. Loss aversion or time discounting have no influence on trustworthiness.

\footnotetext{
27 Uslaner (2008) and Brosig et al. (2011) suggest that a communist regime impacts cooperationnegatively. The effects of communism on trust seem durable (see Rainer and Siedler (2009) and Alesina and Fuchs-Schündeln (2007) on Germany after reunification). Voors et al. (2012) also demonstrate that historical events, such as wars, have long-term effects on social and individual preferences. In the opposite, Esminger (2001) shows with dictator games conducted in Kenya that market experience teaches fairness. Johnson and Mislin (2011) consider that the greater is market integration in a country, the more people learn signals concerning how others expect them to behave in economic and social interactions. Competitive markets favor the formation of shared norms.

${ }_{28}$ Barr (2003) and Schechter (2007) found the same negative relationship and suggest that in rural villages, women are less used to get access to money on their own and are therefore much less willing to give it up.
} 
Result 7: The experience of receiving higher international remittances reduces trustworthiness, while benefiting from domestic remittances increases it. In real life, in the first case people do not feel committed to reciprocate, while the opposite holds with domestic gifts.

Result 8: Trustworthiness is higher in the sample that had a shorter exposure to collectivism.

\section{DISCUSSION AND CONCLUSION}

We have investigated the determinants of trust and trustworthiness in a developing country by conducting an artefactual field experiment in the North and in the South of Vietnam. An originality of our approach is to incorporate risk, time, and social preferences into a single framework of analysis. By measuring the main parameters of the prospect theory and quasi-hyperbolic discounting, we have been able to estimate the correlation between trust, trustworthiness and risk aversion, loss aversion, time discounting rate and present bias.

Our analysis confirms that trust depends both on expectations about others' trustworthiness and on preferences. We show that trust is not affected by probability weighting or the concavity of the utility function. These parameters do not influence the expectations of reciprocity either. These results are in line with those of Eckel and Wilson (2004), Ashraf et al. (2006), Houser et al. (2010), and McEvily et al. (2012). One question remains, though, whether individuals' risk preferences towards lottery choices are able to capture attitudes toward strategic risks (Fehr, 2009). While our design does not allow us to answer this question directly, an interesting result is that loss aversion indirectly influences trust through its negative impact on the expectation of reciprocity. Another interesting result is that trustworthiness is positively correlated with risk aversion although the returning decision does not involve any risk. A possible interpretation is that in real settings individuals know that not reciprocating others' trust entails a risk of social sanctions. If trustees have this in mind when playing the game (although it is played one shot and anonymously), this could suggest that our measure of risk attitudes is able to capture some aspect of social risks.

Regarding time preferences, trust is not affected by the discount rate nor by present bias. More patient individuals are not more trustful than others. In contrast, less present biased individuals are trustworthier possibly because trustees with more time consistent preferences know that 
returning less to increase one's short-run benefit may be detrimental to further long-run interactions.

We have used information on remittances as an indicator of the past experience of receiving gifts, while the international vs. domestic origin of these remittances could be associated with various reciprocity norms. We found that receiving higher international remittances is associated with higher trust but lower expectations and less reciprocity. The trusting behavior in the game may reflect a higher trusting behavior in real life, in particular towards migrants in the family. The negative correlation with expectations suggests that trust is partly motivated by altruism in addition to the expectation of an immediate return. International remittances negatively correlate with trustworthiness, possibly due to the fact that recipients of international remittances do not expect to reciprocate the senders; just like they are not expected by the migrants aboard to return in exchange for the remittances. In contrast, the experience of receiving domestic remittances increases trustworthiness, probably because it conveys a commitment to reciprocate. But reciprocating gifts does not mean that you are more likely to initiate gifts, which could explain that these remittances do not influence trust. These findings have also an important implication for the study of development. While the literature on remittances usually focus on their positive impact in helping to alleviate poverty (see for example Admas and Page, 2005, and Cuong, 2008, about Vietnam), our study gives a new, broader vision on how remittances may influence development through trust and trustworthiness in a society.

Finally, our results show evidence of important regional differences in social preferences. In the North, participants hold lower expectations about others' reciprocity; older individuals are significantly less trustful than the other categories, and trustworthiness is lower than in the South. These findings may be explained by the institutional differences resulting from the separation of the country during a long period of time. A longer exposure to a collectivist system in the North may affect negatively trust, trustworthiness, and expectations, while the historical experience of more than 20 years of a capitalist regime in the South (1954-1975) may have developed a more market orientated mentality with a higher sense of reciprocity and fairness to maintain social 
interactions. However, trust and trustworthiness may also contribute to the evolution of institutions. The interaction between social preferences and institutions constitutes a fascinating avenue for further research.

\section{REFERENCES}

Adams Jr, Richard H. and Page, John."Do international migration and remittances reduce poverty in developing countries?". World Development, October 2005, 33(10), pp. 1645-69.

Aghion, Philippe; Algan, Yann; Cahuc, Pierre and Shleifer, Andrei. "Regulation and Distrust.” The Quarterly Journal of Economics, August 2010, 125(3), pp.1015-49.

Alesina, Alberto and Fuchs-Schündeln, Nicola. "Good-Bye Lenin (or Not?): The Effect of Communism on People's Preferences." American Economic Review, September 2007, 97(4), pp. 1507-28.

Algan, Yann and Cahuc, Pierre. "Inherited Trust and Growth." American Economic Review, December 2010, 100(5), pp. 2060-92.

Andreoni, James and Miller, John H. "Giving according to GARP: An experimental test of the consistency of preferences for altruism.” Econometrica, Mars 2002, 70(2), pp. 737-53.

Arrow, Kenneth. "Gifts and Exchanges", Philosophy and Public Affairs, Summer 1972, 1 (4), pp.343-62.

Ashraf, Nava; Bohnet, Iris and Piankov, Nikita. "Decomposing trust and trustworthiness." Experimental Economics, September 2006, 9(3), pp. 193-208.

Bahry, Donna, and Rick K. Wilson. "Trust in Transitional Societies: Experimental Results from Russia." Paper presented at the American Political Science Association, Chicago, 2004.

Barr, Abigail. "Trust and expected trustworthiness: Experimental evidence from Zimbabwean villages.” The Economic Journal, July 2003,113 (489), pp. 614-30.

Baumgartner, Thomas; Heinrichs, Markus; Vonlanthen, Aline; Fischbacher, Urs and Fehr, Ernst. "Oxytocin Shapes the Neural Circuitry of Trust and Trust Adaptation in Humans." 
Neuron, May 2008, 58(4), pp. 639-50.

Bellemare, Charles and Kröger, Sabine. "On representative social capital". European Economic Review, 2007, 51(1), pp.183-202.

Benhabib, Jess; Bisin, Alberto and Schotter, Andrew. "Present-Bias, Quasi-Hyperbolic Discounting, and Fixed Costs." Games and Economic Behavior, July 2010, 69(2), pp. 205-23.

Ben-Ner, Avner and Putterman, Louis. "Trusting and trustworthiness." Boston University Law Review, June 2001, 81(3), pp. 523-51.

Berg, Joyce; Dickhaut, John and McCabe, Kevin. "Trust, Reciprocity and Social History." Games and Economic Behavior, July 1995, 10(1), pp.122-42.

Bohnet, Iris and Zeckhauser, Richard. "Trust, risk and betrayal." Journal of Economic Behavior \& Organization, December 2004, 55(4), pp. 467-84.

Bohnet, Iris; Greig, Fiona; Herrmann, Benedikt and Zeckhauser, Richard. "Betrayal Aversion: Evidence from Brazil, China, Oman, Switzerland, Turkey, and the United States.” American Economic Review, March 2008, 98(1), pp. 294-310.

Brandts, Jordi and Charness, Gary. "The strategy versus the direct-response method: a first survey of experimental comparisons.” Experimental Economics, September 2011, 14(3), pp. $375-98$.

Brosig-Koch Jeanette; Helbach, Christoph; Ockenfels, Axel and Weimann, Joachim. "Still different after all these years: Solidarity behavior in East and West Germany." Journal of Public Economics, forthcoming. 2012

Brown, Alexander L; Chua, Zhikang Eric and Camerer, Colin F. "Learning and Visceral Temptation in Dynamic Savings Experiments." The Quarterly Journal of Economics, February 2009, 124(1), pp. 197-231.

Camerer, Colin F. Behavioral Game Theory. Princeton, NJ: Princeton University Press, 2003.

Carpenter, Jeffrey P; Daniere, Amrita G. and Takahashi, Lois M. "Cooperation, trust, and 
social capital in Southeast Asian urban slums." Journal of Economic Behavior \& Organization, December 2004, 55 (4), pp. 533-51.

Cook, Karen S and Cooper, Robin M. "Experimental studies of cooperation, trust, and social exchange. " In Ostrom, Elinor and Walker, James. (Eds.), Trust and Reciprocity. New York: Russell Sage, pp. 209-44, 2003.

Cox, James C. "How to Identify Trust and Reciprocity." Games and Economic Behavior, February 2004, 46(2), pp. 260-81.

Cox, James C. and Deck, Cary A. "When Are Women More Generous than Men?" Economic Inquiry, October 2006, 44(4), pp. 587-98.

Croson, Rachel and Buchan, Nancy R. "Gender and Culture: International Experimental Evidence from Trust Games.” American Economic Review, May 1999, 89(2), pp. 386-91.

Croson, Rachel and Gneezy, Uri. "Gender Differences in Preferences." Journal of Economic Literature, June 2009, 47(2), pp.448-74.

Cuong, Nguyen Viet. "Impacts of international and internal remittances on household welfare: Evidence from Viet Nam.” Asia-Pacific Development Journal, June 2009, 16(1), pp.59-92.

Eckel, Catherine C. and Wilson, Rick K. "Is trust a risky decision? "Journal of Economic Behavior \& Organization, December 2004, 55(4), pp. 447-65.

Ensminger, Jean. "Market integration and fairness: Evidence from ultimatum, dictator, and public goods experiments in East Africa," in J. Henrich; R. Boyd; S. Bowles; C. Camerer; E. Fehr; H. Gintis and R. McElreath, eds., Cooperation, reciprocity and punishment: Experiments in 15 small-scale societies. Princeton, NJ: Princeton University Press, 2001.

Fehr, Ernst. "On the economics and biology of trust." Journal of the European Economic Association, April / May 2009, 7(2-3), pp. 235-66.

Fukuyama, Francis. "Social capital and the global economy." Foreign affairs, September/October 1995, 7(95), pp. 89-103.

Glaeser, Edward L; Laibson, David I; Scheinkman, José A. and Soutter, Christine L. 
“Measuring trust.” The Quarterly Journal of Economics, August 2000, 115(3), pp. 811-46.

Guiso, Luigi; Sapienza, Paola and Zingales, Luigi. "Cultural Biases in Economic Exchange?" The Quarterly Journal of Economics, August 2009,124 (3), pp. 1095-131.

Hardin, Russell. Trust and Trustworthiness. New-York: Russell Sage Foundation, 2002.

Holt, Charles A. and Laury, Susan K. "Risk aversion and incentive effects." American Economic Review, December 2002, 92(5), pp. 1644-55.

Houser, Daniel; Schunk, Daniel and Winter, Joachim. "Distinguishing trust from risk: An anatomy of the investment game." Journal of Economic Behavior \& Organization, May 2010, 74(1-2), pp. 72-81.

Johnson, Noel D. and Mislin, Alexandra. "Trust Games: A Meta-Analysis." Journal of Economic Psychology, October 2011, 32(5), pp. 865-89.

Kahneman, Daniel, and Tversky, Amos. "Prospect theory: An analysis of decisions under risk." Econometrica, March 1979, 47 (2), pp. 263-91.

Karlan, Dean S. "Using experimental economics to measure social capital and predict financial decisions.” American Economic Review, December 2005,95(5), pp. 1688-99.

Knack, Stephen and Keefer, Philip. "Does Social Capital Have an Economic Payoff? A Cross-Country Investigation.” The Quarterly Journal of Economics, February 1997, 112(4), pp. 1251-88.

Kosfeld, Michael; Heinrichs, Markus; Zak, Paul J; Fischbacher, Urs and Fehr, Ernst. “Oxytocin increases trust in humans.” Nature, June 2005, 435(2), pp. 673-76.

La Porta, Rafael; Lopez-de-Silanes, Florencio; Shleifer, Andrei, and Vishny, Robert W. “Trust in large organizations.” American Economic Review, May 1997, 87(2), pp. 333-38.

Liu, Elaine. "Time to Change What to Sow: Risk Preferences and Technology Adoption Decisions of Cotton Farmers in China." Review of Economics and Statistics, forthcoming.

McEvily,Bill; Radzevick, Joseph and Weber, Roberto A. "Whom do you trust and how much does it cost? An experiment on the measurement of trust." Games and Economic Behavior, 
January 2012, 74(1), pp. 285-98.

Naef, Michael and Schupp, Jürgen. "Measuring Trust: Experiments and Surveys in Contrast and Combination.” IZA Discussion Paper 4087, Bonn. 2009

Neace, M.B. "The impact of low trust on economic development: the case of Latin America."Review of Policy Research, September 2004, 21(5), pp. 699-713.

Niimi, Yoko; Pham, Thai Hung and Reilly, Barry. Determinants of remittances: Recent evidence using data on internal migrants in Vietnam. World Bank Policy Research Working Paper 4586. 2008.

Parks, Craig and Vu, Anh D. "Social dilemma behavior of individuals from highly individualist and collectivist cultures." Journal of Conflict Resolution, December 1994, 38(4), pp. 708-18.

Prelec, Drazen. “The Probability Weighting Function.” Econometrica, May 1998, 66(3), pp. 497-527.

Putman, Robert D. Making democracy work: Civic traditions in modern Italy. Princeton, NJ: Princeton University Press. 1993.

Rainer, Helmut and Siedler, Thomas. “Does democracy foster trust?” Journal of Comparative Economics, June 2009, 37(2), pp. 251-69.

Schechter, Laura. "Traditional Trust Measurement and the Risk Confound: An Experiment in Rural Paraguay.” Journal of Economic Behavior \& Organization, January 2007, 62(2), pp. 272-92.

Snijders, Chris and Keren, Gideon. "Determinants of trust.” In: D. V. Budescu; I. Erev and R. Zwick, eds., Games and Behavior: Essays in Honor of Amnon Rapoport. Mahwah, NJ: Lawrence Erlbaum Associates, 1999, pp. 355-83.

Song, Fei, Cadsby, C. Bram and Bi, Yunyun. "Trust, Reciprocity, and Guanxi in China: An Experimental Investigation.” Discussion paper 12-04, University of Guelph. 2012.

Stark, Oded and Lucas, Robert E. B. "Migration, Remittances, and the Family." Economic 
Development and Cultural Change, April 1998, 36(3), pp. 465-81.

Sutter, Matthias and Kocher, Martin. "Trust and trustworthiness across different age groups." Games and Economic Behavior, May 2007, 59(2), pp. 364-82.

Tanaka, Tomomi; Camerer, Colin F. and Nguyen, Quang. "Risk and Time Preferences: Linking Experimental and Household Survey Data from Vietnam." American Economic Review, March 2010, 100(1), pp. 557-71.

Tilly, Charles. Trust and rule. Cambridge: Cambridge University Press, 2005.

Tversky, Amos and Kahneman, Daniel. "Advances in prospect theory: Cumulative representation of uncertainty." Journal of Risk and Uncertainty, October 1992, 5(4), pp. 297-323.

Uslaner, Eric M. "Where you stand depends upon where your grandparents sat: the inheritability of general trust." Public Opinion Quarterly, 2008, 72(4), pp. 725-40.

Voors, Maarten J; Nillesen, Eleonora E.M; Bulte, Erwin H; Lensink, Robert; Verwimp, Philip and Van Soest, Daan P. "Violent Conflict and Behavior: a Field Experiment in Burundi." American Economic Review, April 2012, 102(2), pp. 941-64.

Wakker, Peter P. Prospect Theory: For Risk and Ambiguity. Cambridge: Cambridge University Press, 2010.

Yamagishi, Toshio; Cook, Karen S. and Watabe, Motoki. "Uncertainty, trust and commitment formation in the United States and Japan." American Journal of Sociology July 1998, 104(1), pp. 165-94.

Zak, Paul J. andKnack, Stephen. "Trust and growth." The Economic Journal, April 2001, 470(11), pp. 295-321. 
Trust and Trustworthiness under the Prospect Theory:

A field experiment in Vietnam

Quang Nguyen, Marie Claire Villeval, Hui Xu

\section{Supplement Materials For Online Publication}

Appendix 1. Experimental instructions

Appendix 2. Background information on the experimental sample

Appendix 3. Estimates of the parameter for the curvature of power value function, of the probability sensitivity parameter, and of the loss aversion parameter

Appendix 4. Determinants of the trusters' expected return from trustees 


\section{Appendix 1. Experimental instructions (original in Vietnamese)}

Thank you all for taking the time to come today. Today's session will take as much as 4 hours, so if you think you will not be able to stay that long, let us know now. Before we begin, I want to make some general comments about what we are doing here today and explain the rules that we must follow. We will be playing some games with money. Whatever money you win in the games will be yours to keep and take home.

We will be playing three games. We are about to begin the first game. It is important that you listen as carefully as possible.

If you have any question, please raise your hand and we will answer your questions in private. Please do not ask questions to the other participants or talk about the game with them. This is very important. Please be sure that you obey this rule.

\section{Game 1}

In this game, your earnings will depend partly on your decisions and partly on chance. There are three series of questions. Series 1 consists of 12 questions. Series 2 consists of 14 questions. Series 3 consists of 7 questions. So, there are 33 questions in total. In each question, we will offer you two Plans: Plan A and Plan B. We would like you to choose either Plan A or Plan B for each question. After you complete the record sheet, we put 33 balls in a bingo cage and draw one numbered ball to select 1 question out of 33 questions. We will play the selected question for real money. For example, if the number 21 ball is drawn, we will play Question 21 for real money.

Once the question is determined, we will put 10 balls in the cage and play the selected question.

Let's practice with the following question. Please choose either Plan A or Plan B.

\section{Example}

This example is the same as series 1 (questions 1-12). Please look at the record sheet.

There are two Plans, A and B. There are 10 balls numbered (1), (2), (3), (4), (5), (6), (7), (8), (9), and (10) in a bingo cage. You should choose either A or B. Let's look at question 1.

\begin{tabular}{|l|l|l|}
\hline & \multicolumn{1}{|c|}{ Plan A } & \multicolumn{1}{|c|}{ Plan B } \\
\hline 1 & VND 40,000 if (1) (2) (3) & VND 68,000 if (1) \\
& VND 10,000 if(4) (5) (6) (7) (8) (9) (1) & VND 5,000if (2) (3) (4) (5) (6) (7) (8) (9) (1) \\
\hline
\end{tabular}

We will draw one numbered ball out of the cage.

If Number 1 ball comes out, those who chose Plan A will receive VND 40,000 and those who chose Plan B will receive VND 68,000.

If Number 3 ball comes out, those who chose Plan A will receive VND 40,000 and those who chose Plan B will receive VND 5,000.

If Number 6 ball comes out, those who chose Plan A will receive VND 10,000 and those who chose Plan B will receive VND 5,000 .

Suppose you choose Plan A from question 1 to question 5 and Plan B from question 6 to question 12. 
Then, you should fill in the record sheet as follows:

\begin{tabular}{|c|c|c|}
\hline & Plan A & Plan B \\
\hline $\begin{array}{c}1- \\
1\end{array}$ & $\begin{array}{l}\text { VND40,000 if (1) (2) (3) } \\
\text { VND } 10,000 \text { if(4) (5) (6) (7) (8) (9) (10) }\end{array}$ & $\begin{array}{l}\text { VND } 68,000 \text { if (1) } \\
\text { VND } 5,000 \text { if (2) (3) (4) (5) (6) (7) (8) (9) (10) }\end{array}$ \\
\hline $\begin{array}{l}1- \\
2\end{array}$ & $\begin{array}{l}\text { NND40,000 if (1) (2) (3) } \\
\text { VND } 10,000 \text { if(4) (5) (6) (7) (8) (9) (10) }\end{array}$ & $\begin{array}{l}\text { VND } 75,000 \text { if (1) } \\
\text { VND } 5,000 \text { if (2) (3) (4) (5) (6) (7) (8) (9) (10) }\end{array}$ \\
\hline $\begin{array}{l}1- \\
3\end{array}$ & $\begin{array}{l}\text { NND40,000 if (1) (2) (3) } \\
\text { VND } 10,000 \text { if(4) (5) (6) (7) (8) (9) (10) }\end{array}$ & $\begin{array}{l}\text { VND } 83,000 \text { if (1) } \\
\text { VND } 5,000 \text { if (2) (3) (4) (5) (6) (7) (8) (9) (10) }\end{array}$ \\
\hline $\begin{array}{l}1- \\
4\end{array}$ & $\begin{array}{l}\text { ND40,000 if (1) (2) (3) } \\
\text { VND } 10,000 \text { if(4) (5) (6) (7) (8) (9) (10) }\end{array}$ & $\begin{array}{l}\text { VND } 93,000 \text { if (1) } \\
\text { VND } 5,000 \text { if (2) (3) (4) (5) (6) (7) (8) (9) (10) }\end{array}$ \\
\hline $\begin{array}{l}1- \\
5\end{array}$ & $\begin{array}{l}\text { NND40,000 if (1) (2) (3) } \\
\text { VND 10,000 if(4) (5) (6) (7) (8) (9) (10) }\end{array}$ & $\begin{array}{l}\text { VND } 106,500 \text { if (1) } \\
\text { VND } 5,000 \text { if (2) (3) (4) (5) (6) (7) (8) (9) (10) }\end{array}$ \\
\hline $\begin{array}{l}1- \\
6\end{array}$ & $\begin{array}{l}\text { VND 40,000 if (1) (2) (3) } \\
\text { VND 10,000 if(4) (5) (6) (7) (8) (9) (10) }\end{array}$ & $\begin{array}{l}\text { YND } 25,000 \text { if (1) } \\
\text { VND } 5,000 \text { if (2) (3) (4) (5) (6) (7) (8) (9) (1) }\end{array}$ \\
\hline $\begin{array}{l}1- \\
7\end{array}$ & $\begin{array}{l}\text { VND 40,000 if (1) (2) (3) } \\
\text { VND } 10,000 \text { if(4) (5) (6) (7) (8) (9) (10) }\end{array}$ & $\begin{array}{l}\text { YND } 150,000 \text { if (1) } \\
\operatorname{VND~} 5,000 \text { if (2) (3) (4) (5) (6) (7) (8) (9) (1) }\end{array}$ \\
\hline $\begin{array}{l}1- \\
8\end{array}$ & $\begin{array}{l}\text { VND 40,000 if (1) (2) (3) } \\
\text { VND } 10,000 \text { if(4) (5) (6) (7) (8) (9) (10) }\end{array}$ & $\begin{array}{l}\text { YND } 185,000 \text { if (1) } \\
\text { VND } 5,000 \text { if (2) (3) (4) (5) (6) (7) (8) (9) (1) }\end{array}$ \\
\hline $\begin{array}{l}1- \\
9\end{array}$ & $\begin{array}{l}\text { VND 40,000 if(1) (2) (3) } \\
\text { VND } 10,000 \text { if(4) (5) (6) (7) (8) (9) (10) }\end{array}$ & $\begin{array}{l}\text { YND } 220,000 \text { if (1) } \\
\text { VND } 5,000 \text { if (2) (3) (4) (5) (6) (7) (8) (9) (1) }\end{array}$ \\
\hline $\begin{array}{l}1- \\
10\end{array}$ & $\begin{array}{l}\text { VND 40,000 if (1) (2) (3) } \\
\text { VND 10,000 if(4) (5) (6) (7) (8) (9) (10) }\end{array}$ & $\begin{array}{l}\text { YND 300,000 if (1) } \\
\text { VND 5,000 if (2) (3) (4) (5) (6) (7) (8) (9) (1) }\end{array}$ \\
\hline $\begin{array}{l}1- \\
11\end{array}$ & $\begin{array}{l}\text { VND 40,000 if (1) (2) (3) } \\
\text { VND } 10,000 \text { if(4) (5) (6) (7) (8) (9) (10) }\end{array}$ & $\begin{array}{l}\text { YND 400,000 if (1) } \\
\operatorname{VND} 5,000 \text { if (2) (3) (4) (5) (6) (7) (8) (9) (11) }\end{array}$ \\
\hline $\begin{array}{l}1- \\
12\end{array}$ & $\begin{array}{l}\text { VND 40,000 if (1) (2) (3) } \\
\text { VND } 10,000 \text { if(4) (5) (6) (7) (8) (9) (10) }\end{array}$ & $\begin{array}{l}\text { YND } 600,000 \text { if (1) } \\
\text { VND } 5,000 \text { if (2) (3) (4) (5) (6) (7) (8) (9) (1) }\end{array}$ \\
\hline
\end{tabular}

I choose plan A for questions $1-5$

I choose plan B for questions

$6-12$.

If you choose Plan A for all 12 questions, please fill in the record sheet as follows: 


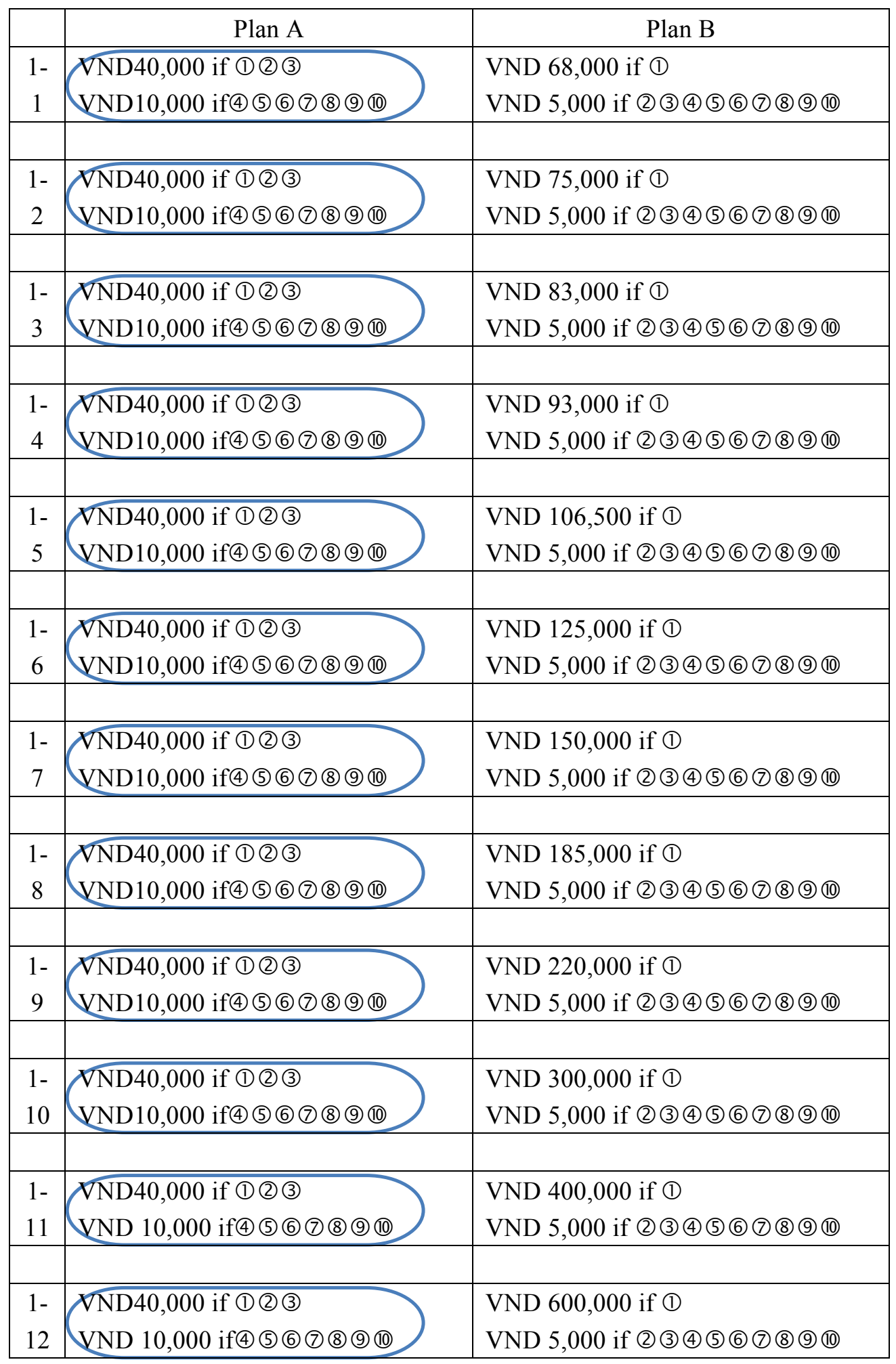

I choose plan A for questions $1-12$

I choose plan B for questions

If you choose Plan B for all 12 questions, please fill in the record sheet as follows: 


\begin{tabular}{|c|c|c|}
\hline & Plan A & Plan B \\
\hline $\begin{array}{l}1- \\
1\end{array}$ & $\begin{array}{l}\text { VND 40,000 if (1) (2) (3) } \\
\text { VND } 10,000 \text { if(4) (5) (6) (7) (8) (9) (10) }\end{array}$ & $\begin{array}{l}\mathrm{YND} 68,000 \text { if (1) } \\
\operatorname{VND} 5,000 \text { if (2) (3) (4) (5) (6) (7) (8) (9) (10) }\end{array}$ \\
\hline $\begin{array}{l}1- \\
2\end{array}$ & $\begin{array}{l}\text { VND 40,000 if (1) (2) (3) } \\
\text { VND } 10,000 \text { if (4) (5) (6) (7) (8) (9) (10) }\end{array}$ & $\begin{array}{l}\text { WND } 75,000 \text { if (1) } \\
\text { VND } 5,000 \text { if (2) (3) (4) (5) (6) (7) (8) (9) (10) }\end{array}$ \\
\hline $\begin{array}{l}1- \\
3\end{array}$ & $\begin{array}{l}\text { VND 40,000 if (1) (2) (3) } \\
\text { VND } 10,000 \text { if(4) (5) (6) (7) (8) (9) (10) }\end{array}$ & $\begin{array}{l}\text { VND } 83,000 \text { if (1) } \\
\text { VND } 5,000 \text { if (2) (3) (4) (5) (6) (7) (8) (9) (1) }\end{array}$ \\
\hline $\begin{array}{l}1- \\
4\end{array}$ & $\begin{array}{l}\text { VND 40,000 if (1) (2) (3) } \\
\text { VND } 10,000 \text { if(4) (5) (6) (7) (8) (9) (10) }\end{array}$ & $\begin{array}{l}\text { YND } 93,000 \text { if (1) } \\
\text { WND } 5,000 \text { if (2) (3) (4) (5) (6) (7) (8) (9) (10) }\end{array}$ \\
\hline $\begin{array}{l}1- \\
5\end{array}$ & $\begin{array}{l}\text { VND 40,000 if (1) (2) (3) } \\
\text { VND } 10,000 \text { if(4) (5) (6) (7) (8) (9) (10) }\end{array}$ & $\begin{array}{l}\text { YND } 106,500 \text { if (1) } \\
\text { VND } 5,000 \text { if (2) (3) (4) (5) (6) (7) (8) (9) (10) }\end{array}$ \\
\hline $\begin{array}{c}1- \\
6\end{array}$ & $\begin{array}{l}\text { VND 40,000 if (1) (2) (3) } \\
\text { VND } 10,000 \text { if(4) (5) (6) (7) (8) (9) (1) }\end{array}$ & $\begin{array}{l}\text { YND } 125,000 \text { if (1) } \\
\operatorname{VND} 5,000 \text { if (2) (3) (4) (5) (6) (7) (8) (9) (10) }\end{array}$ \\
\hline $\begin{array}{l}1- \\
7\end{array}$ & $\begin{array}{l}\text { VND 40,000 if (1) (2) (3) } \\
\text { VND } 10,000 \text { if(4) (5) (6) (7) (8) (9) (1) }\end{array}$ & $\begin{array}{l}\text { WND } 150,000 \text { if (1) } \\
\text { VND } 5,000 \text { if (2) (3) (4) (5) (6) (7) (8) (9) (10) }\end{array}$ \\
\hline $\begin{array}{l}1- \\
8\end{array}$ & $\begin{array}{l}\text { VND 40,000 if (1) (2) (3) } \\
\text { VND } 10,000 \text { if(4) (5) (6) (7) (8) (9) (1) }\end{array}$ & $\begin{array}{l}\text { WND } 185,000 \text { if (1) } \\
\text { WND } 5,000 \text { if (2) (3) (4) (5) (6) (7) (8) (9) (10) }\end{array}$ \\
\hline $\begin{array}{l}1- \\
9\end{array}$ & $\begin{array}{l}\text { VND 40,000 if(1) (2) (3) } \\
\text { VND 10,000 if(4) (5) (6) (7) (8) (9) (10) }\end{array}$ & $\begin{array}{l}\text { YND } 220,000 \text { if (1) } \\
\operatorname{VND} 5,000 \text { if (2) (3) (4) (5) (6) (7) (8) (9) (10) }\end{array}$ \\
\hline $\begin{array}{l}1- \\
10\end{array}$ & $\begin{array}{l}\text { VND 40,000 if (1) (2) (3) } \\
\text { VND } 10,000 \text { if(4) (5) (6) (7) (8) (9) (1) }\end{array}$ & $\begin{array}{l}\text { YND } 300,000 \text { if (1) } \\
\text { VND } 5,000 \text { if (2) (3) (4) (5) (6) (7) (8) (9) (10) }\end{array}$ \\
\hline $\begin{array}{l}1- \\
11\end{array}$ & $\begin{array}{l}\text { VND 40,000 if (1) (2) (3) } \\
\text { VND } 10,000 \text { if(4) (5) (6) (7) (8) (9) (1) }\end{array}$ & $\begin{array}{l}\text { YND } 400,000 \text { if (1) } \\
\text { VND } 5,000 \text { if (2) (3) (4) (5) (6) (7) (8) (9) (10) }\end{array}$ \\
\hline $\begin{array}{l}1- \\
12\end{array}$ & $\begin{array}{l}\text { VND 40,000 if (1) (2) (3) } \\
\text { VND } 10,000 \text { if (4) (5) (6) (7) (8) (9) (10) }\end{array}$ & $\begin{array}{l}\text { VND } 600,000 \text { if (1) } \\
\operatorname{VND} 5,000 \text { if (2) (3) (4) (5) (6) (7) (8) (9) (10) }\end{array}$ \\
\hline
\end{tabular}

I choose plan A for questions 1-

I choose plan B for questions $\quad 1 \quad-12$.

Now, look at Series 3. In Series 3, you can lose money. 


\section{Example}

This example is the same as question 27.

There are two Plans, A and B. There are 10 balls numbered (1), (2), (3), (4), (5), (6), (7), (8), (9), and (10) in a bingo cage. You should choose either A or B.

\begin{tabular}{|l|l|l|}
\hline & \multicolumn{1}{|c|}{ Plan A } & \multicolumn{1}{|c|}{ Plan B } \\
\hline 27 & $\begin{array}{l}\text { Receive VND 25,000 if (1) (2) (3) (4) (5) } \\
\text { Lose VND 4,000 if (6) (7) (8) (9) (10 }\end{array}$ & $\begin{array}{l}\text { Receive VND 30,000 if (1) (2) (3) (4) (5) } \\
\text { Lose VND 21,000 if (6) (7) (8) (9) (1) }\end{array}$ \\
\hline
\end{tabular}

If Number 1, 2, 3, 4 or 5 ball comes out, those who chose Plan A will receive VND 25,000 and those who chose Plan B will receive VND 30,000.

If Number 6, 7, 8, 9 or 10 ball comes out, those who chose Plan A will lose VND 4,000 and those who chose Plan B will lose VND 21,000.

We will subtract money from your earnings from the other games. 


\section{Series 1}

\section{Record Sheet - Game 1}

\begin{tabular}{|c|c|c|}
\hline & Plan A & Plan B \\
\hline $\begin{array}{c}1- \\
1\end{array}$ & $\begin{array}{l}\text { VND 40,000 if (1) (2) (3) } \\
\text { VND } 10,000 \text { if(4) (5) (6) (7) (8) (9) (10) }\end{array}$ & $\begin{array}{l}\text { VND } 68,000 \text { if (1) } \\
\text { VND } 5,000 \text { if (2) (3) (4) (5) (6) (7) (8) (9) (10) }\end{array}$ \\
\hline $\begin{array}{l}1- \\
2\end{array}$ & $\begin{array}{l}\text { VND 40,000 if (1) (2) (3) } \\
\text { VND } 10,000 \text { if (4) (5) (6) (7) (8) (9) (10) }\end{array}$ & $\begin{array}{l}\text { VND } 75,000 \text { if (1) } \\
\text { VND } 5,000 \text { if (2) (3) (4) (5) (6) (7) (8) (9) (1) }\end{array}$ \\
\hline $\begin{array}{l}1- \\
3\end{array}$ & $\begin{array}{l}\text { VND 40,000 if (1) (2) (3) } \\
\text { VND } 10,000 \text { if(4) (5) (6) (7) (8) (9) (10) }\end{array}$ & $\begin{array}{l}\text { VND } 83,000 \text { if (1) } \\
\text { VND } 5,000 \text { if (2) (3) (4) (5) (6) (7) (8) (9) (1) }\end{array}$ \\
\hline $\begin{array}{l}1- \\
4\end{array}$ & $\begin{array}{l}\text { VND 40,000 if (1) (2) (3) } \\
\text { VND 10,000 if(4) (5) (6) (7) (8) (9) (10) }\end{array}$ & $\begin{array}{l}\text { VND 93,000 if (1) } \\
\text { VND 5,000 if (2) (3) (4) (5) (6) (7) (8) (9) (1) }\end{array}$ \\
\hline $\begin{array}{l}1- \\
5\end{array}$ & $\begin{array}{l}\text { VND 40,000 if (1) (2) (3) } \\
\text { VND } 10,000 \text { if(4) (5) (6) (7) (8) (9) (10) }\end{array}$ & $\begin{array}{l}\text { VND } 106,500 \text { if (1) } \\
\text { VND } 5,000 \text { if (2) (3) (4) (5) (6) (7) (8) (9) (1) }\end{array}$ \\
\hline $\begin{array}{c}1- \\
6\end{array}$ & $\begin{array}{l}\text { VND 40,000 if (1) (2) (3) } \\
\text { VND } 10,000 \text { if(4) (5) (6) (7) (8) (9) (10) }\end{array}$ & $\begin{array}{l}\text { VND } 125,000 \text { if (1) } \\
\text { VND } 5,000 \text { if (2) (3) (4) (5) (6) (7) (8) (9) (1) }\end{array}$ \\
\hline $\begin{array}{l}1- \\
7\end{array}$ & $\begin{array}{l}\text { VND 40,000 if (1) (2) (3) } \\
\text { VND } 10,000 \text { if(4) (5) (6) (7) (8) (9) (1) }\end{array}$ & $\begin{array}{l}\text { VND } 150,000 \text { if (1) } \\
\text { VND } 5,000 \text { if (2) (3) (4) (5) (6) (7) (8) (9) (1) }\end{array}$ \\
\hline $\begin{array}{l}1- \\
8\end{array}$ & $\begin{array}{l}\text { VND 40,000 if (1) (2) (3) } \\
\text { VND 10,000 if(4) (5) (6) (7) (8) (9) (10) }\end{array}$ & $\begin{array}{l}\text { VND } 185,000 \text { if (1) } \\
\text { VND } 5,000 \text { if (2) (3) (4) (5) (6) (7) (8) (9) (1) }\end{array}$ \\
\hline $\begin{array}{l}1- \\
9\end{array}$ & $\begin{array}{l}\text { VND 40,000 if(1) (2) (3) } \\
\text { VND 10,000 if(4) (5) (6) (7) (8) (9) (10) }\end{array}$ & $\begin{array}{l}\text { VND } 220,000 \text { if (1) } \\
\text { VND } 5,000 \text { if (2) (3) (4) (5) (6) (7) (8) (9) (1) }\end{array}$ \\
\hline $\begin{array}{l}1- \\
10\end{array}$ & $\begin{array}{l}\text { VND 40,000 if (1) (2) (3) } \\
\text { VND } 10,000 \text { if(4) (5) (6) (7) (8) (9) (10) }\end{array}$ & $\begin{array}{l}\text { VND } 300,000 \text { if (1) } \\
\text { VND 5,000 if (2) (3) (4) (5) (6) (7) (8) (9) (10) }\end{array}$ \\
\hline $\begin{array}{l}1- \\
11\end{array}$ & $\begin{array}{l}\text { VND 40,000 if (1) (2) (3) } \\
\text { VND } 10,000 \text { if(4) (5) (6) (7) (8) (9) (10) }\end{array}$ & $\begin{array}{l}\text { VND } 400,000 \text { if (1) } \\
\text { VND } 5,000 \text { if (2) (3) (4) (5) (6) (7) (8) (9) (1) }\end{array}$ \\
\hline $\begin{array}{l}1- \\
12\end{array}$ & $\begin{array}{l}\text { VND 40,000 if (1) (2) (3) } \\
\text { VND } 10,000 \text { if(4) (5) (6) (7) (8) (9) (10) }\end{array}$ & $\begin{array}{l}\text { VND } 600,000 \text { if (1) } \\
\text { VND } 5,000 \text { if (2) (3) (4) (5) (6) (7) (8) (9) (1) }\end{array}$ \\
\hline
\end{tabular}

\section{Answer:}

I choose Plan A for questions 1 -

I choose Plan B for questions

$-12$. 


\section{Series 2}

\begin{tabular}{|l|l|l|}
\hline & \multicolumn{1}{|c|}{ Plan A } & \multicolumn{1}{|c|}{ Plan B } \\
\hline $2-$ & VND 40,000 if (1) (2) (3) (4) (5) (6) (7) (8) (9) & VND 54,000 if (1) (2) (3) (4) (5) (6) (7) \\
13 & VND 30,000 if (10) & VND 5,000 if (8) (9) (1) \\
\hline
\end{tabular}

\begin{tabular}{|l|l|l|}
\hline $\begin{array}{l}2- \\
14\end{array}$ & VND 40,000 if (1) (2) (3) (4) (5) (6) (7) (8) (9) & VND 56,000 if (1) (2) (3) (4) (5) (6) (7) \\
VND 30,000 if (1) & VND 5,000 if (8) (9) (10) \\
\hline
\end{tabular}

\begin{tabular}{|l|l|l|}
\hline $\begin{array}{l}2- \\
15\end{array}$ & VND 40,000 if (1) (2) (3) (4) (5) (6) (7) (8) (9) & VND 58,000 if (1) (2) (3) (4) (5) (6) (7) \\
\hline
\end{tabular}

\begin{tabular}{|l|l|l|}
\hline $\begin{array}{l}2- \\
16\end{array}$ & VND 40,000 if (1) (2) (3) (4) (5) (6) (7) (8) (9) & VND 60,000 if (1) (2) (3) (4) (5) (6) (7) \\
\hline
\end{tabular}

\begin{tabular}{|l|l|l|}
\hline $\begin{array}{l}2- \\
17\end{array}$ & VND 40,000 if (1) (2) (3) (4) (5) (6) (7) (8) (9) & VND 62,000 if (1) (2) (3) (4) (5) (6) (7) \\
VND 30,000 if (1) & VND 5,000 if (8) (9) (10) \\
\hline
\end{tabular}

\begin{tabular}{|l|l|l|}
\hline $\begin{array}{l}2- \\
18\end{array}$ & VND 40,000 if (1) (2) (3) (4) (5) (6) (7) (8) (9) & VND 65,000 if (1) (2) (3) (4) (5) (6) (7) \\
& VND 30,000 if (10) & VN,000 if (8) (9) (10) \\
\hline
\end{tabular}

\begin{tabular}{|l|l|l|}
\hline $\begin{array}{l}2- \\
19\end{array}$ & VND 40,000 if (1) (2) (3) (4) (5) (6) (7) (8) (9) & VND 68,000 if (1) (2) (3) (4) (5) (6) (7) \\
VND 30,000 if (10) & VND 5,000 if (8) (9) (10) \\
\hline
\end{tabular}

\begin{tabular}{|l|l|l|}
\hline $\begin{array}{l}2- \\
20\end{array}$ & VND 40,000 if (1) (2) (3) (4) (5) (6) (7) (8) (9) & VND 72,000 if (1) (2) (3) (4) (5) (6) (7) \\
VND 30,000 if (1) & VND 5,000 if (8) (9) (10) \\
\hline
\end{tabular}

\begin{tabular}{|l|l|l|}
\hline $\begin{array}{l}2- \\
21\end{array}$ & VND 40,000 if (1) (2) (3) (4) (5) (6) (7) (8) (9) & VND 77,000 if (1) (2) (3) (4) (5) (6) (7) \\
\hline & & VND 5,000 if (8) (9) (10) \\
\hline $2-$ & VND 40,000 if (1) (2) (3) (4) (5) (6) (7) (8) (9) & VND 83,000 if (1) (2) (3) (4) (5) (6) (7) \\
22 & VND 30,000 if (10) & VND 5,000 if (8) (9) (10) \\
\hline
\end{tabular}

\begin{tabular}{|l|l|l|}
\hline $\begin{array}{l}2- \\
23\end{array}$ & VND 40,000 if (1) (2) (3) (4) (5) (6) (7) (8) (9) & VND 90,000 if (1) (2) (3) (4) (5) (6) (7) \\
VND 30,000 if (1) & VND 5,000 if (8) (9) (10) \\
\hline
\end{tabular}

\begin{tabular}{|l|l|l|}
\hline $\begin{array}{l}2- \\
24\end{array}$ & VND 40,000 if (1) (2) (3) (4) (5) (6) (7) (8) (9) & VND 100,000 if (1) (2) (3) (4) (5) (6) (7) \\
& VND 30,000 if (10) & VN,000 if (8) (9) (10) \\
\hline
\end{tabular}

\begin{tabular}{|l|l|l|}
\hline $\begin{array}{l}2- \\
25\end{array}$ & VND 40,000 if (1) (2) (3) (4) (5) (6) (7) (8) (9) & VND 110,000 if (1) (2) (3) (4) (5) (6) (7) \\
VND 30,000 if (1) & VND 5,000 if (8) (9) (10) \\
\hline
\end{tabular}




\begin{tabular}{|l|l|l|}
\hline $2-$ & VND 40,000 if (1) (2) (3) (4) (5) (6) (7) (8) (9) & VND 130,000 if (1) (2) (3) (4) (5) (6) (7) \\
26 & VND 30,000 if (10) & VND 5,000 if (8) (9) (10) \\
\hline
\end{tabular}

Answer:

I choose Plan A for questions 13 -

I choose Plan B for questions

$-26$.

\section{Series 3}

\begin{tabular}{|l|l|l|}
\hline & \multicolumn{1}{|c|}{ Plan A } & \multicolumn{1}{|c|}{ Plan B } \\
\hline 3- & Receive VND 25,000 if (1) (2) (3) (4) (5) & Receive VND 30,000 if (1) (2) (3) (4) (5) \\
27 & Lose VND 4,000 if(6) (7) (8) (9) (1) & Lose VND 21,000 if(6) (7) (8) (9) (10) \\
\hline
\end{tabular}

\begin{tabular}{|l|l|l|}
\hline $3-$ & Receive VND 5,000 if (1) (2) (3) (4) (5) & Receive VND 30,000 if (1) (2) (3) (4) (5) \\
28 & Lose VND 4,000 if(6) (7) (8) (9) (1) & Lose VND 21,000 if(6) (7) (8) (9) (10) \\
\hline
\end{tabular}

\begin{tabular}{|l|l|l|}
\hline 3- & Receive VND 1,000 if (1) (2) (3) (4) (5) & Receive VND 30,000 if (1) (2) (3) (4) (5) \\
29 & Lose VND 4,000 if(6) (7) (8) (9) (1) & Lose VND 21,000 if(6) (7) (8) (9) (10) \\
\hline
\end{tabular}

\begin{tabular}{|l|l|l|}
\hline $\begin{array}{l}3- \\
30\end{array}$ & Receive VND 1,000 if (1) (2) (3) (4) (5) & Receive VND 30,000 if (1) (2) (3) (4) (5) \\
\hline
\end{tabular}

\begin{tabular}{|l|l|l|}
\hline $3-$ & ReceiveVND 1,000 if (1) (2) (3) (4) (5) & Receive VND 30,000 if (1) (2) (3) (4) (5) \\
31 & Lose VND 8,000 if(6) (7) (8) (9) (1) & Lose VND 16,000 if(6) (7) (8) (9) (10) \\
\hline
\end{tabular}

\begin{tabular}{|l|l|l|}
\hline 3- & Receive VND 1,000if (1) (2) (3) (4) (5) & Receive VND 30,000if (1) (2) (3) (4) (5) \\
32 & Lose VND 8,000 if(6) (7) (8) (9) (10 & Lose VND 14,000 if(6) (7) (8) (9) (10) \\
\hline
\end{tabular}

\begin{tabular}{|l|l|l|}
\hline $3-$ & Receive VND 1,000 if (1) (2) (3) (4) (5) & Receive VND 30,000 if (1) (2) (3) (4) (5) \\
33 & Lose VND 8,000 if(6) (7) (8) (9) (10) & Lose VND 11,000 if(6) (7) (8) (9) (10) \\
\hline
\end{tabular}

\section{Answer:}

I choose Plan A for questions 27 -

I choose Plan B for questions $-33$. 


\section{Game 2}

In this game, you will receive money either today or sometime in the future, depending on the choices you make. There are 75 questions. In each question, we will offer you two plans: Plan A and Plan B. We would like you to choose either Plan A or Plan B for each question.

\section{Example}

This example is the same as question 1. Please refer to the record sheet.

There are 2 Plans, A and B, offered to you.

If you choose Plan A, you will receive VND 20,000 tomorrow.

If you choose Plan B, you will receive VND 120,000 in 1 week.

Questions 1 to 5 are one series. If you choose Plan B for question 1 to question 3, and Plan A for questions 4 and 5, please answer as follows:

\begin{tabular}{|l|l|l|}
\hline & \multicolumn{1}{|c|}{ Plan A } & \multicolumn{1}{c|}{ Plan B } \\
\hline 1 & Receive VND 20,000 tomorrow & Receive VND 120,000 in 1 week \\
\hline 2 & Receive VND 40,000 tomorrow & Receive VND 120,000 in 1 week \\
\hline 3 & Receive VND 60,000 tomorrow & Receive VND 120,000 in 1 week \\
\hline 4 & Receive VND 80,000 tomorrow & Receive VND 120,000 in 1 week \\
\hline 5 & Reeeive VND 100,000 tomorrow & Receive VND 120,000 in 1 week \\
\hline
\end{tabular}

I choose Plan A for 4- 5 I choose Plan B for 1-3

If you choose Plan A for all 5 questions, please answer as follows:

\begin{tabular}{|c|c|c|c|}
\hline & \multicolumn{2}{|c|}{ Plan A } & Plan B \\
\hline 1 & \multicolumn{2}{|c|}{ Receive VND 20,000 tomorrow } & Receive VND 120,000 in 1 week \\
\hline 2 & \multicolumn{2}{|c|}{ Receive VND 40,000 tomorrow } & Receive VND 120,000 in 1 week \\
\hline 3 & \multicolumn{2}{|c|}{ Receive VND 60,000 tomorrow } & Receive VND 120,000 in 1 week \\
\hline 4 & \multicolumn{2}{|c|}{ Receive VND 80,000 tomorrow } & Receive VND 120,000 in 1 week \\
\hline 5 & \multicolumn{2}{|c|}{ Reeeive VND 100,000 tomerrow } & Receive VND 120,000 in 1 week \\
\hline & se Plan A for & -5 & I choose Plan \\
\hline
\end{tabular}

If you choose Plan B for all 5 questions, please answer as follows:

\begin{tabular}{|l|l|l|}
\hline & \multicolumn{1}{|c|}{ Plan A } & \multicolumn{1}{|c|}{ Plan B } \\
\hline 1 & Receive VND 20,000 tomorrow & Receive VND 120,000 in 1 week \\
\hline 2 & Receive VND 40,000 tomorrow & Receive VND 120,000 in 1 week \\
\hline 3 & Receive VND 60,000 tomorrow & Receive VND 120,000 in 1 week \\
\hline 4 & Receive VND 80,000 tomorrow & Receive VND 120,000 in 1 week \\
\hline 5 & Receive VND 100,000 tomorrow & Receive VND 120,000 in 1 week \\
\hline
\end{tabular}

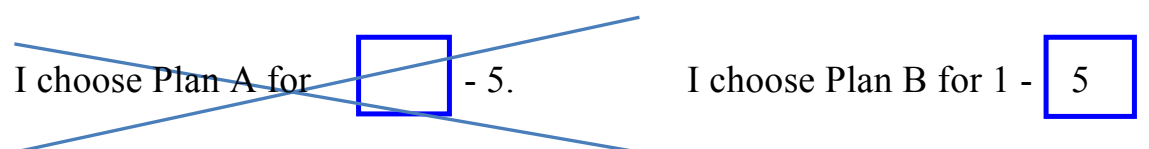

Please choose either Plan A or Plan B for each of the 75 questions. You will be paid based on one of your 
choices.

We will put 75 balls in a bingo cage and draw one ball to determine which question will be played for real money. For example, if the number 21 ball is drawn, we will do Question 21 for real money. Suppose Question 21 is selected, and you choose Plan A in Question 21, you will be paid VND 50,000 tomorrow. If you chose Plan B in Question 21, you will receive VND 300,000 in 1 month.

At the end of the experiment, we will discuss whom the money should be entrusted to until you pick up the money. It could be the commune office, the president of women's associations, or someone whom you all trust. For each of you, we will put the money in an envelope and write down your name, the amount of money you should receive, and the date you should pick it up from the person, and seal it. The entrusted person will keep all the envelopes until the pick up date. We will sign the letter of agreement among the researchers, the entrusted person and all of you. 
Record Sheet - Game 2

\begin{tabular}{|l|l|l|}
\hline & \multicolumn{1}{|c|}{ Plan A } & \multicolumn{1}{c|}{ Plan B } \\
\hline 1 & Receive VND 20,000 tomorrow & Receive VND 120,000 in 1 week \\
\hline 2 & Receive VND 40,000 tomorrow & Receive VND 120,000 in 1 week \\
\hline 3 & Receive VND 60,000 tomorrow & Receive VND 120,000 in 1 week \\
\hline 4 & Receive VND 80,000 tomorrow & Receive VND 120,000 in 1 week \\
\hline 5 & Receive VND 100,000 tomorrow & Receive VND 120,000 in 1 week \\
\hline
\end{tabular}

I choose Plan A for $\square-5 . \quad$ I choose Plan B for 1-

\begin{tabular}{|l|l|l|}
\hline & \multicolumn{1}{|c|}{ Plan A } & \multicolumn{1}{c|}{ Plan B } \\
\hline 6 & Receive VND 20,000 tomorrow & Receive VND 120,000 in 1 month \\
\hline 7 & Receive VND 40,000 tomorrow & Receive VND 120,000 in 1 month \\
\hline 8 & Receive VND 60,000 tomorrow & Receive VND 120,000 in 1 month \\
\hline 9 & Receive VND 80,000 tomorrow & Receive VND 120,000 in 1 month \\
\hline 10 & Receive VND 100,000 tomorrow & Receive VND 120,000 in 1 month \\
\hline
\end{tabular}

I choose Plan A for - $10 . \quad$ I choose Plan B for 6 -

\begin{tabular}{|l|l|l|}
\hline & \multicolumn{1}{|c|}{ Plan A } & \multicolumn{1}{c|}{ Plan B } \\
\hline 11 & Receive VND 20,000 tomorrow & Receive VND 120,000 in 3months \\
\hline 12 & Receive VND 40,000 tomorrow & Receive VND 120,000 in 3months \\
\hline 13 & Receive VND 60,000 tomorrow & Receive VND 120,000 in 3months \\
\hline 14 & Receive VND 80,000 tomorrow & Receive VND 120,000 in 3months \\
\hline 15 & Receive VND100,000 tomorrow & Receive VND 120,000 in 3months \\
\hline
\end{tabular}

\begin{tabular}{|c|c|c|}
\hline \multicolumn{2}{|c|}{ I choose Plan A for } & I choose Plan B for 11- \\
\hline & Plan A & Plan B \\
\hline 16 & Receive VND 50,000 tomorrow & Receive VND 300,000 in 1 week \\
\hline 17 & Receive VND 100,000 tomorrow & Receive VND 300,000 in 1 week \\
\hline 18 & Receive VND 150,000 tomorrow & Receive VND 300,000 in 1 week \\
\hline 19 & Receive VND 200,000 tomorrow & Receive VND 300,000 in 1 week \\
\hline 20 & Receive VND 250,000 tomorrow & Receive VND 300,000 in 1 week \\
\hline
\end{tabular}

I choose Plan A for $\square-20 . \quad$ I choose Plan B for 16- 


\begin{tabular}{|l|l|l|}
\hline & \multicolumn{1}{|c|}{ Plan A } & \multicolumn{1}{c|}{ Plan B } \\
\hline 21 & Receive VND 50,000 tomorrow & Receive VND 300,000 in 1 month \\
\hline 22 & Receive VND 100,000 tomorrow & Receive VND 300,000 in 1 month \\
\hline 23 & Receive VND 150,000 tomorrow & Receive VND 300,000 in 1 month \\
\hline 24 & Receive VND 200,000 tomorrow & Receive VND 300,000 in 1 month \\
\hline 25 & Receive VND 250,000 tomorrow & Receive VND 300,000 in 1 month \\
\hline
\end{tabular}

I choose Plan A for - 25. I choose Plan B for 21 -

\begin{tabular}{|l|l|l|}
\hline & \multicolumn{1}{|c|}{ Plan A } & \multicolumn{1}{c|}{ Plan B } \\
\hline 26 & Receive VND 50,000 tomorrow & Receive VND 300,000 in 3months \\
\hline 27 & Receive VND 100,000 tomorrow & Receive VND 300,000 in 3months \\
\hline 28 & Receive VND 150,000 tomorrow & Receive VND300,000 in 3months \\
\hline 29 & Receive VND 200,000 tomorrow & Receive VND 300,000 in 3months \\
\hline 30 & Receive VND 250,000 tomorrow & Receive VND 300,000 in 3months \\
\hline
\end{tabular}

I choose Plan A for - 30. I choose Plan B for $26-$

\begin{tabular}{|l|l|l|}
\hline & \multicolumn{1}{|c|}{ Plan A } & \multicolumn{1}{c|}{ Plan B } \\
\hline 31 & Receive VND 5,000 tomorrow & Receive VND 30,000 in 1 week \\
\hline 32 & Receive VND 10,000 tomorrow & Receive VND 30,000 in 1 week \\
\hline 33 & Receive VND 15,000 tomorrow & Receive VND 30,000 in 1 week \\
\hline 34 & Receive VND 20,000 tomorrow & Receive VND 30,000 in 1 week \\
\hline 35 & Receive VND 25,000 tomorrow & Receive VND 30,000 in 1 week \\
\hline
\end{tabular}

I choose Plan A for

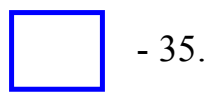

I choose Plan B for 31 -

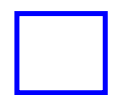

\begin{tabular}{|l|l|l|}
\hline & \multicolumn{1}{|c|}{ Plan A } & \multicolumn{1}{c|}{ Plan B } \\
\hline 36 & Receive VND 5,000 tomorrow & Receive VND 30,000 in 1 month \\
\hline 37 & Receive VND 10,000 tomorrow & Receive VND 30,000 in 1 month \\
\hline 38 & Receive VND 15,000 tomorrow & Receive VND 30,000 in 1 month \\
\hline 39 & Receive VND 20,000 tomorrow & Receive VND 30,000 in 1 month \\
\hline 40 & Receive VND 25,000 tomorrow & Receive VND 30,000 in 1 month \\
\hline
\end{tabular}

I choose Plan A for - 40. I choose Plan B for 36 -

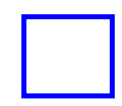




\begin{tabular}{|l|l|l|}
\hline & \multicolumn{1}{|c|}{ Plan A } & \multicolumn{1}{c|}{ Plan B } \\
\hline 41 & Receive VND 5,000 tomorrow & Receive VND 30,000 in 3 months \\
\hline 42 & Receive VND 10,000 tomorrow & Receive VND 30,000 in 3 months \\
\hline 43 & Receive VND 15,000 tomorrow & Receive VND 30,000 in 3 months \\
\hline 44 & Receive VND 20,000 tomorrow & Receive VND 30,000 in 3 months \\
\hline 45 & Receive VND 25,000 tomorrow & Receive VND 30,000 in 3 months \\
\hline
\end{tabular}

I choose Plan A for - 45. I choose Plan B for 41 -

\begin{tabular}{|l|l|l|}
\hline & \multicolumn{1}{|c|}{ Plan A } & \multicolumn{1}{c|}{ Plan B } \\
\hline 46 & Receive VND 40,000 tomorrow & Receive VND 240,000 in 3 days \\
\hline 47 & Receive VND 80,000 tomorrow & Receive VND 240,000 in 3 days \\
\hline 48 & Receive VND 120,000 tomorrow & Receive VND 240,000 in 3 days \\
\hline 49 & Receive VND 160,000 tomorrow & Receive VND 240,000 in 3 days \\
\hline 50 & Receive VND 200,000 tomorrow & Receive VND 240,000 in 3 days \\
\hline
\end{tabular}

I choose Plan A for $\square-50 . \quad$ I choose Plan B for 46 -

\begin{tabular}{|l|l|l|}
\hline & \multicolumn{1}{|c|}{ Plan A } & \multicolumn{1}{c|}{ Plan B } \\
\hline 51 & Receive VND 40,000 tomorrow & Receive VND 240,000 in 2weeks \\
\hline 52 & Receive VND 80,000 tomorrow & Receive VND 240,000 in 2weeks \\
\hline 53 & Receive VND 120,000 tomorrow & Receive VND 240,000 in 2weeks \\
\hline 54 & Receive VND 160,000 tomorrow & Receive VND 240,000 in 2weeks \\
\hline 55 & Receive VND 200,000 tomorrow & Receive VND 240,000 in 2weeks \\
\hline
\end{tabular}

I choose Plan A for

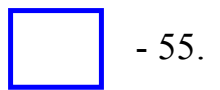

I choose Plan B for 51 -

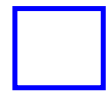

\begin{tabular}{|l|l|l|}
\hline & \multicolumn{1}{|c|}{ Plan A } & \multicolumn{1}{c|}{ Plan B } \\
\hline 56 & Receive VND 40,000 tomorrow & Receive VND 240,000 in 2months \\
\hline 57 & Receive VND 80,000 tomorrow & Receive VND 240,000 in 2months \\
\hline 58 & Receive VND 120,000 tomorrow & Receive VND 240,000 in 2months \\
\hline 59 & Receive VND 160,000 tomorrow & Receive VND 240,000 in 2months \\
\hline 60 & Receive VND 200,000 tomorrow & Receive VND 240,000 in 2months \\
\hline
\end{tabular}

I choose Plan A for - 60. I choose Plan B for 56 -

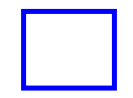




\begin{tabular}{|l|l|l|}
\hline & \multicolumn{1}{|c|}{ Plan A } & \multicolumn{1}{c|}{ Plan B } \\
\hline 61 & Receive VND 10,000 tomorrow & Receive VND 60,000 in 3 days \\
\hline 62 & Receive VND 20,000 tomorrow & Receive VND 60,000 in 3 days \\
\hline 63 & Receive VND 30,000 tomorrow & Receive VND 60,000 in 3 days \\
\hline 64 & Receive VND 40,000 tomorrow & Receive VND 60,000 in 3 days \\
\hline 65 & Receive VND 50,000 tomorrow & Receive VND 60,000 in 3 days \\
\hline
\end{tabular}

I choose Plan A for - 65. I choose Plan B for 61 -

\begin{tabular}{|l|l|l|}
\hline & \multicolumn{1}{|c|}{ Plan A } & \multicolumn{1}{c|}{ Plan B } \\
\hline 66 & Receive VND 10,000 tomorrow & Receive VND 60,000 in 2 weeks \\
\hline 67 & Receive VND 20,000 tomorrow & Receive VND 60,000 in 2 weeks \\
\hline 68 & Receive VND 30,000 tomorrow & Receive VND 60,000 in 2 weeks \\
\hline 69 & $\begin{array}{l}\text { Receive VND 40,000 tomorrow } \\
\text { VND }\end{array}$ & Receive VND 60,000 in 2 weeks \\
\hline 70 & Receive VND 50,000 tomorrow & Receive VND 60,000 in 2 weeks \\
\hline
\end{tabular}

I choose Plan A for $\square-70 . \quad$ I choose Plan B for 66 -

\begin{tabular}{|l|l|l|}
\hline & \multicolumn{1}{|c|}{ Plan A } & \multicolumn{1}{c|}{ Plan B } \\
\hline 71 & Receive VND 10,000 tomorrow & Receive VND 60,000 in 2 months \\
\hline 72 & Receive VND 20,000 tomorrow & Receive VND 60,000 in 2 months \\
\hline 73 & Receive VND 30,000 tomorrow & Receive VND 60,000 in 2 months \\
\hline 74 & Receive VND 40,000 tomorrow & Receive VND 60,000 in 2 months \\
\hline 75 & Receive VND 50,000 tomorrow & Receive VND 60,000 in 2 months \\
\hline
\end{tabular}

I choose Plan A for $\square-75 . \quad$ I choose Plan B for 71 - 


\section{Game 3}

This experiment is played by pairs. Each pair is made up of a person called A and another person, called B. Each of you will be paired with one of the other participants. However, nobody knows in advance with whom you will be playing.

We will provide each of you with a name tag which color is white or red. After you have completed the decisions for this game, we will toss a coin. If the head appears, those with a red name tag will be person A, whereas those with a white name tag will be person B. If the tail appears, those with a red name tag will be person $\mathrm{B}$, whereas those with a white name tag will be person $\mathrm{A}$.

\section{We will proceed with this experiment as follows.}

Each of you will be given VND 20,000. You will make decisions depending on whether you are person Aor person B. Please note that at this moment you do not know if you are person A or person B. Thus, pay attention to the decision you make both when you play the role of A and when you play the role of B.

\section{You play the role of person A:}

You can sendsome amount of yourVND 20,000to person B. You cansend VND 5,000, VND 10,000,VND 15,000 , VND 20,000, or nothing. This amount will then be tripled and given to person B. Person B can then send some money to you. Note that person Bcansend you any amount of money that she or he wants.

\section{You play the role of person B:}

In addition to the VND 20,000 we give you at the beginning of this experiment, you will receive some amount of money from person A. Youcan refer to Tables 1-4 when making your decisions. However, you can totally decide how much money to send to person A. These amounts can be different from those in Tables 1-4.

\section{How tomake decisions?}

Each of you will be given a record sheet to write down your decisions. You will make decisions for two scenarios. In the first scenario, you play the role of person A. In the second scenario, you play the role of person B. Please note that you do not know whether you are person A or person B at this moment.

After all of you have finished making decisions, we will toss a coin to know which role you are assigned to. For example, if the head appears and your name tag is in red, you will be person A. In this case, the actual payment you receive will depend on the decision you made in the first scenario. Likewise, if you are person B, your actual payment will depend on the decisions you made in the second scenario. Thus, be careful to make decisions for both scenarios.

After having collected the record sheets from all of you, we will toss a coin to know if you are person A or person B. If you are person A, we will randomly assign you with someone else who is person B. Your payoff will depend on the decision you make in the first scenario as well as on person B's decisions for thesecond scenario. If you are person B, we will randomly assign you with someone who is person A. Your payoff will depend on the decisions you make in the second scenario as well as on person A's decision for the first scenario.

Now, let's work together on the following example. We prepared Tables 1-4for your references only.

\section{Example}

Please refer to Table 1. Suppose that person Asends VND 5,000to person B. This amount is tripled. Hence, person B receives VND 15,000 $(3 \times 5,000=15,000)$ in addition to the initial amount of VND 20,000. At this point, person A has VND 15,000 (20,000 - 5,000) and B has VND 35,000 (20,000 $+15,000)$. Now, person B will decide to send money to A, and if so, how much.

If person Bsends zero, then person A will earnVND 15,000, and person B will earnVND 35,000 in this 
game.

If person Bsends VND 10,000, then person A will earn VND 25,000 $(15,000+10,000)$, and person B will earn VND 25,000 $(35,000$ - 10,000) in this game.

Please note that person $\mathrm{A}$ is allowed to send one of the following amounts: VND 5,000, VND 10,000, VND 15,000, VND 20,000, or zero. Person B can decide to send any amount of money he/she wants.

\section{Record Sheets}

You will make decisions based on whether you are person A or person B. You could be person A or person B, so be careful with your decision.

\section{You play the role of person $A$.}

You have VND 20,000. You have the chance to send a portion of VND 20,000 to person B. You could send VND 5,000, VND 10,000, VND 15,000, VND 20,000, or nothing. Whatever amount you decide to send to person $\mathrm{B}$ will be tripled before it is passed on to person $\mathrm{B}$.

\section{You play the role of person $B$.}

As person B, you are also given VND 20,000. Beside, you will receive some money from person A. You must decide how much money you want to send back to person A, or you may send nothing.

\section{How is the game conducted?}

After collecting all the record sheets, we will randomly divide you into two groups: group A (play the role of person A) or group B (play the role of person B). The members of both groups should be in equal number. If the total number of participants is odd, then one will play with the project assistant.

The amount will be sent based on your decision in the record sheet below. 


\section{Record Sheet - Person A}

I want to send VND $\quad 0$

$$
\begin{aligned}
& 5,000 \\
& 10,000 \\
& 15,000 \\
& 20,000
\end{aligned}
$$

$(\ldots \ldots \ldots \ldots \ldots \ldots)$ to person B.

The money will be tripled (x3), so person B will get VND (.... ) in addition to his/her initial VND 20,000.

I think person B will return VND (.... .) to me.

\section{Your decision will remain confidential.}

\section{Record Sheet - Person B}

If person A sends me nothing, of 0 to VND 20,000

I will send him/her VND (...

If person A sends me VND 5,000, of 0 to VND35,000 $(20,000+5,000 \times 3)$

I will return VND (<smiles>[VH2]</smiles>

If person A sends me VND 10,000, of 0 to VND 50,000 $(20,000+10,000 \times 3)$

I will return VND ( ..).

If person A sends me VND 15,000, of 0 to VND 65,000 $(20,000+15,000 \times 3)$

I will return VND ...).

If person A sends me VND 20,000, of 0 to VND 80,000 $(20,000+20,000 \times 3)$

I will return VND $(\ldots \ldots \ldots \ldots \ldots \ldots)$.

\section{Your decisions will remain confidential.}


Table 1

Suppose you send VND 5,000to person B. So, B receives a total of 3 x 5,000 $=$ VND 15,000 on top of VDN 20,000 we give to her or him.

\begin{tabular}{|l|c|c|c|}
\hline & The money you earn & The money B earns & Total \\
\hline If B sends nothing & 15,000 & 35,000 & 50,000 \\
\hline If B sendsVND 5,000 & 20,000 & 30,000 & 50,000 \\
\hline If B sends VND 10,000 & 25,000 & 25,000 & 50,000 \\
\hline If B sends VND 15,000 & 30,000 & 20,000 & 50,000 \\
\hline
\end{tabular}

Table 2

Suppose you send VND 10,000to person B. So, B receives a total of $3 \times 10,000=$ VND30,000 on top of VDN 20,000 we give to her or him.

\begin{tabular}{|l|c|c|c|}
\hline & The money you earn & The money B earns & Total \\
\hline If B sends nothing & 10,000 & 50,000 & 60,000 \\
\hline If B sends VND 5,000 & 15,000 & 45,000 & 60,000 \\
\hline If B sends VND 10,000 & 20,000 & 40,000 & 60,000 \\
\hline If B sends VND 15,000 & 25,000 & 35,000 & 60,000 \\
\hline If B sends VND 20,000 & 30,000 & 30,000 & 60,000 \\
\hline If B sends VND 25,000 & 35,000 & 25,000 & 60,000 \\
\hline If B sends VND 30,000 & 40,000 & 20,000 & 60,000 \\
\hline
\end{tabular}

Table 3

Suppose you send VND 15,000to person B. So, B receives a total of 3 x 15,000 = VND 45,000 on top of VND 20,000 we give to her or him.

\begin{tabular}{|l|c|c|c|}
\hline & The money you earn & The money B earns & Total \\
\hline If B sends nothing & 5,000 & 65,000 & 70,000 \\
\hline If B sends VND 5,000 & 10,000 & 60,000 & 70,000 \\
\hline If B sends VND 10,000 & 15,000 & 55,000 & 70,000 \\
\hline If B sends VND 15,000 & 20,000 & 50,000 & 70,000 \\
\hline If B sends VND 20,000 & 25,000 & 45,000 & 70,000 \\
\hline If B sends VND 25,000 & 30,000 & 40,000 & 70,000 \\
\hline If B sends VND 30,000 & 35,000 & 35,000 & 70,000 \\
\hline
\end{tabular}

Table 4

Suppose you send VND 20,000to person B. So, B receives a total of 3 x 20,000 = VND 60,000 on top of VND 20,000 we give to her or him.

\begin{tabular}{|l|c|c|c|}
\hline & The money you earn & The money B earns & Total \\
\hline If B sends nothing & 0 & 80,000 & 80,000 \\
\hline If B sends VND 10,000 & 10,000 & 70,000 & 80,000 \\
\hline If B sends VND 20,000 & 20,000 & 60,000 & 80,000 \\
\hline If B sends VND 30,000 & 30,000 & 50,000 & 80,000 \\
\hline If B sends VND 40,000 & 40,000 & 40,000 & 80,000 \\
\hline If B sends VND 50,000 & 50,000 & 30,000 & 80,000 \\
\hline If B sends VND 60,000 & 60,000 & 20,000 & 80,000 \\
\hline
\end{tabular}




\section{Appendix 2. Background information on the experimental sample}

Table A1 is a summary statistics about the participants' income and receipt of international and domestic remittances. These statistics come from the VHLSS 2002.

The average yearly household income of our participants is KVND 38,732. This differs across regions with the North having a higher average yearly household income than the South (KVND 42,373vs. KVND 34,950).Moreover, the income distribution is less equal in the North than in the South (S.D.: 51,616vs. 28,171).

Both international and domestic remittances are common in Vietnam. International remittances are dominated by emigrants to North America, followed by Europe, Australia, and Asia (Pfau and Long, 2008b). Regarding international remittance receivers, Pfau and Long (2008b) state that female-headed households receive more remittances. Concerning the senders, children provided the most remittances to female-headed households (41.4\%) followed by siblings and nieces or nephews (35.\%), and $4.8 \%$ of the total international remittances (by value) arriving to female-headed households came from spouses. Concerning internal remittance senders, a report by the United Nations Population Fund (UNFPA)29 in 2007 estimates that roughly half of the migrants sent money back home, and female migrants tend to send more than male migrants. In terms of receivers in home communities, based on the VHLSS 1997/1998, Pfau and Long (2008a) describe that children/children-in-law receive the biggest amounts (45.3\%) followed by siblings and nieces or nephews (18.9\%), and finally parents $(17.7 \%)$.

Table A1. Descriptive statistics on participants' income and received remittances (2002)

\begin{tabular}{|c|c|c|c|c|c|c|c|}
\hline & Mean & $\begin{array}{c}\% \text { in } \\
\text { average } \\
\text { income }\end{array}$ & $\begin{array}{c}\text { \%of } \\
\text { households } \\
\text { with that } \\
\text { source }\end{array}$ & $\begin{array}{l}\text { Mean among } \\
\text { households } \\
\text { with income } \\
\text { from that } \\
\text { source }\end{array}$ & $\begin{array}{l}\text { Mean } \\
\text { income } \\
\text { of the } \\
\text { category }\end{array}$ & $\begin{array}{l}\% \text { in income } \\
\text { of households } \\
\text { with income } \\
\text { from that } \\
\text { source }\end{array}$ & $\begin{array}{l}\text { Mean income } \\
\text { without all } \\
\text { remittances of } \\
\text { the category }\end{array}$ \\
\hline \multicolumn{8}{|l|}{ Total sample } \\
\hline Income & 38,732 & - & - & - & - & - & 36,387 \\
\hline Domestic remittances & 905 & $2 \%$ & $73 \%$ & 1,214 & 32,473 & $3.7 \%$ & 30,342 \\
\hline International remittances & 1,439 & $4 \%$ & $7.3 \%$ & 20,807 & 53,360 & $39 \%$ & 31,417 \\
\hline \multicolumn{8}{|l|}{ South } \\
\hline Income & 34,950 & - & - & - & - & - & 31,151 \\
\hline Domestic remittances & 865 & $2 \%$ & $71 \%$ & 1,227 & 31,164 & $4 \%$ & 28,060 \\
\hline International remittances & 2,934 & $7.6 \%$ & $14 \%$ & 20,807 & 53,360 & $39 \%$ & 31,417 \\
\hline \multicolumn{8}{|l|}{ North } \\
\hline Income & 42,373 & - & - & - & - & - & 41.429 \\
\hline Domestic remittances & 944 & $2.4 \%$ & $75 \%$ & 1,254 & 33,654 & $3.7 \%$ & 32,400 \\
\hline
\end{tabular}

Notes: a) Source: VHLSS2002. b)Units are KVND. c) Income and remittances are of whole household annually.d) North has no international remittances.e) Both domestic and international remittances include not only money received, but also the equivalent monetary value of in-kind presents.

Table A1 indicates that while domestic remittances are notable ( $73 \%$ households) and equally distributed between South and North in terms of the amount of remittances and the proportion of receivers, we find only a small proportion of households (7\%) having received international remittances in 2002, with all of them being from the South (14\% among the southern participants). The average amount of international remittance is significantly largerthan the average amount of domestic remittances (KVND 20,807 vs.

${ }^{29}$ The report is entitled "Internal migration: Opportunities and challenges for socio-economic development in Viet Nam" (http://www.vn.one.un.org). 
1,214). The domestic remittancesrepresent only $3.7 \%$ of the beneficiaries' household income on average whereas the international remittancesrepresent $39 \%$ of the beneficiaries' household income.

Domestic and international remittances have different impacts on the economic condition of rural households. Those households with domestic remittances are poorer than households without domestic remittances; on the contrary, households with international remittances are richer than households without international remittances.

It is worth mentioning thatin the South, when remittances are included as part of income, the average income for households with international remittances is much higher than both the average income of all households and households with domestic remittances. This suggests that international remittances are an extremely important income source that contributes to the disparity of income. However, the average income of households with domestic remittances is still lower than the average income; this is also true in the North. 


\section{Appendix 3. Estimates of the parameter for the curvature of power value function and of the probability sensitivity parameter}

Table A2. Switching points (questions) in series 1 and 2 and the ranges of $\sigma$ (parameter for the curvature of power value function)

\begin{tabular}{|c|c|c|c|c|c|c|c|c|c|c|c|c|c|}
\hline \multirow[b]{3}{*}{ Series 2} & \multicolumn{13}{|c|}{ Switching question in series 1} \\
\hline & 1 & 2 & & 3 & 3 & 2 & 4 & & 5 & & 6 & & 7 \\
\hline & 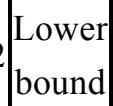 & $\begin{array}{l}\text { Lower } \\
\text { bound }\end{array}$ & $\begin{array}{l}\text { Upper } \\
\text { bound }\end{array}$ & $\begin{array}{l}\text { Lower } \\
\text { bound }\end{array}$ & $\begin{array}{l}\text { Upper } \\
\text { bound }\end{array}$ & $\begin{array}{l}\text { Lower } \\
\text { bound }\end{array}$ & $\begin{array}{l}\text { Upper } \\
\text { bound }\end{array}$ & $\begin{array}{l}\text { Lower } \\
\text { bound }\end{array}$ & $\begin{array}{l}\text { Upper } \\
\text { bound }\end{array}$ & $\begin{array}{l}\text { Lower } \\
\text { bound }\end{array}$ & $\begin{array}{l}\text { Upper } \\
\text { bound }\end{array}$ & $\begin{array}{l}\text { Lower } \\
\text { bound }\end{array}$ & $\begin{array}{l}\text { Upper } \\
\text { bound }\end{array}$ \\
\hline 1 & 1.4 & 1.33 & & 1.27 & & 1.21 & & 1.15 & & 1.05 & & 0.97 & \\
\hline 2 & 1.3 & 1.23 & 1.39 & 1.17 & 1.3 & 1.12 & 1.22 & 1.06 & 1.15 & 0.99 & 1.09 & 0.91 & 1.03 \\
\hline 3 & 1.22 & 1.16 & 1.29 & 1.1 & 1.21 & 1.05 & 1.14 & 0.99 & 1.07 & 0.92 & 1 & 0.85 & 0.94 \\
\hline 4 & 1.16 & 1.11 & 1.21 & 1.05 & 1.13 & 1 & 1.06 & 0.93 & 1 & 0.86 & 0.94 & 0.79 & 0.88 \\
\hline 5 & 1.12 & 1.05 & 1.13 & 0.99 & 1.05 & 0.93 & 1 & 0.87 & 0.94 & 0.8 & 0.89 & 0.75 & 0.83 \\
\hline 6 & 1.04 & 0.97 & 1.07 & 0.91 & 1.01 & 0.86 & 0.96 & 0.8 & 0.91 & 0.74 & 0.85 & 0.69 & 0.8 \\
\hline 7 & 0.96 & 0.9 & 1 & 0.85 & 0.95 & 0.8 & 0.89 & 0.75 & 0.84 & 0.7 & 0.79 & 0.65 & 0.74 \\
\hline 8 & 0.89 & 0.84 & 0.95 & 0.79 & 0.9 & 0.74 & 0.84 & 0.69 & 0.79 & 0.64 & 0.74 & 0.6 & 0.68 \\
\hline 9 & 0.82 & 0.77 & 0.88 & 0.73 & 0.82 & 0.68 & 0.77 & 0.63 & 0.73 & 0.59 & 0.68 & 0.54 & 0.62 \\
\hline 10 & 0.76 & 0.71 & 0.81 & 0.67 & 0.75 & 0.62 & 0.71 & 0.58 & 0.66 & 0.53 & 0.62 & 0.49 & 0.56 \\
\hline 11 & 0.7 & 0.66 & 0.74 & 0.62 & 0.69 & 0.57 & 0.64 & 0.53 & 0.6 & 0.48 & 0.56 & 0.44 & 0.51 \\
\hline 12 & 0.68 & 0.59 & 0.67 & 0.55 & 0.62 & 0.51 & 0.58 & 0.47 & 0.54 & 0.43 & 0.5 & 0.38 & 0.46 \\
\hline 13 & 0.6 & 0.55 & 0.6 & 0.51 & 0.55 & 0.47 & 0.52 & 0.43 & 0.48 & 0.39 & 0.45 & 0.35 & 0.4 \\
\hline 14 & 0.51 & 0.47 & 0.55 & 0.43 & 0.51 & 0.39 & 0.47 & 0.35 & 0.43 & 0.31 & 0.39 & 0.28 & 0.35 \\
\hline Never & 0.41 & & 0.47 & & 0.43 & & 0.4 & & 0.37 & & 0.34 & & 0.3 \\
\hline
\end{tabular}


(cont.)

\begin{tabular}{|c|c|c|c|c|c|c|c|c|c|c|c|}
\hline \multirow{3}{*}{$\begin{array}{c}\text { Series } \\
2\end{array}$} & \multicolumn{2}{|c|}{8} & \multicolumn{2}{|c|}{9} & \multicolumn{2}{|c|}{10} & \multicolumn{2}{|c|}{11} & \multicolumn{2}{|c|}{12} & \multirow{3}{*}{$\begin{array}{l}\text { Never } \\
\text { Upper } \\
\text { bound }\end{array}$} \\
\hline & Lower & Upper & Lower & Upper & Lower & Upper & Lower & Upper & Lower & Upper & \\
\hline & bound & bound & bound & bound & bound & bound & bound & bound & bound & bound & \\
\hline 1 & 0.91 & & 0.86 & & 0.79 & & 0.74 & & 0.88 & & 0.62 \\
\hline 2 & 0.84 & 0.97 & 0.8 & 0.9 & 0.72 & 0.85 & 0.66 & 0.77 & 0.61 & 0.71 & 0.52 \\
\hline 3 & 0.78 & 0.89 & 0.75 & 0.83 & 0.67 & 0.77 & 0.62 & 0.72 & 0.56 & 0.66 & 0.47 \\
\hline 4 & 0.73 & 0.83 & 0.7 & 0.77 & 0.62 & 0.72 & 0.57 & 0.66 & 0.52 & 0.61 & 0.43 \\
\hline 5 & 0.7 & 0.78 & 0.65 & 0.73 & 0.6 & 0.68 & 0.55 & 0.62 & 0.5 & 0.57 & 0.39 \\
\hline 6 & 0.64 & 0.73 & 0.59 & 0.67 & 0.54 & 0.64 & 0.49 & 0.57 & 0.45 & 0.53 & 0.36 \\
\hline 7 & 0.6 & 0.68 & 0.55 & 0.62 & 0.51 & 0.59 & 0.46 & 0.52 & 0.41 & 0.48 & 0.32 \\
\hline 8 & 0.55 & 0.62 & 0.5 & 0.57 & 0.46 & 0.54 & 0.41 & 0.48 & 0.37 & 0.44 & 0.29 \\
\hline 9 & 0.5 & 0.57 & 0.45 & 0.52 & 0.41 & 0.49 & 0.36 & 0.43 & 0.32 & 0.4 & 0.26 \\
\hline 10 & 0.45 & 0.52 & 0.4 & 0.47 & 0.36 & 0.45 & 0.32 & 0.39 & 0.27 & 0.36 & 0.23 \\
\hline 11 & 0.4 & 0.46 & 0.36 & 0.42 & 0.32 & 0.4 & 0.28 & 0.35 & 0.23 & 0.32 & 0.19 \\
\hline 12 & 0.34 & 0.41 & 0.31 & 0.37 & 0.26 & 0.36 & 0.24 & 0.31 & 0.2 & 0.27 & 0.15 \\
\hline 13 & 0.31 & 0.36 & 0.27 & 0.33 & 0.23 & 0.3 & 0.2 & 0.26 & 0.16 & 0.22 & 0.1 \\
\hline 14 & 0.24 & 0.32 & 0.22 & 0.28 & 0.18 & 0.27 & 0.16 & 0.22 & 0.13 & 0.19 & 0.08 \\
\hline Never & & 0.27 & & 0.24 & & 0.2 & & 0.16 & & 0.13 & 0.04 \\
\hline
\end{tabular}


Table A3. Switching points (questions) in series 1 and 2 and the rangesof $\alpha$ (probability sensitivity parameter in Prelec's weighting function)

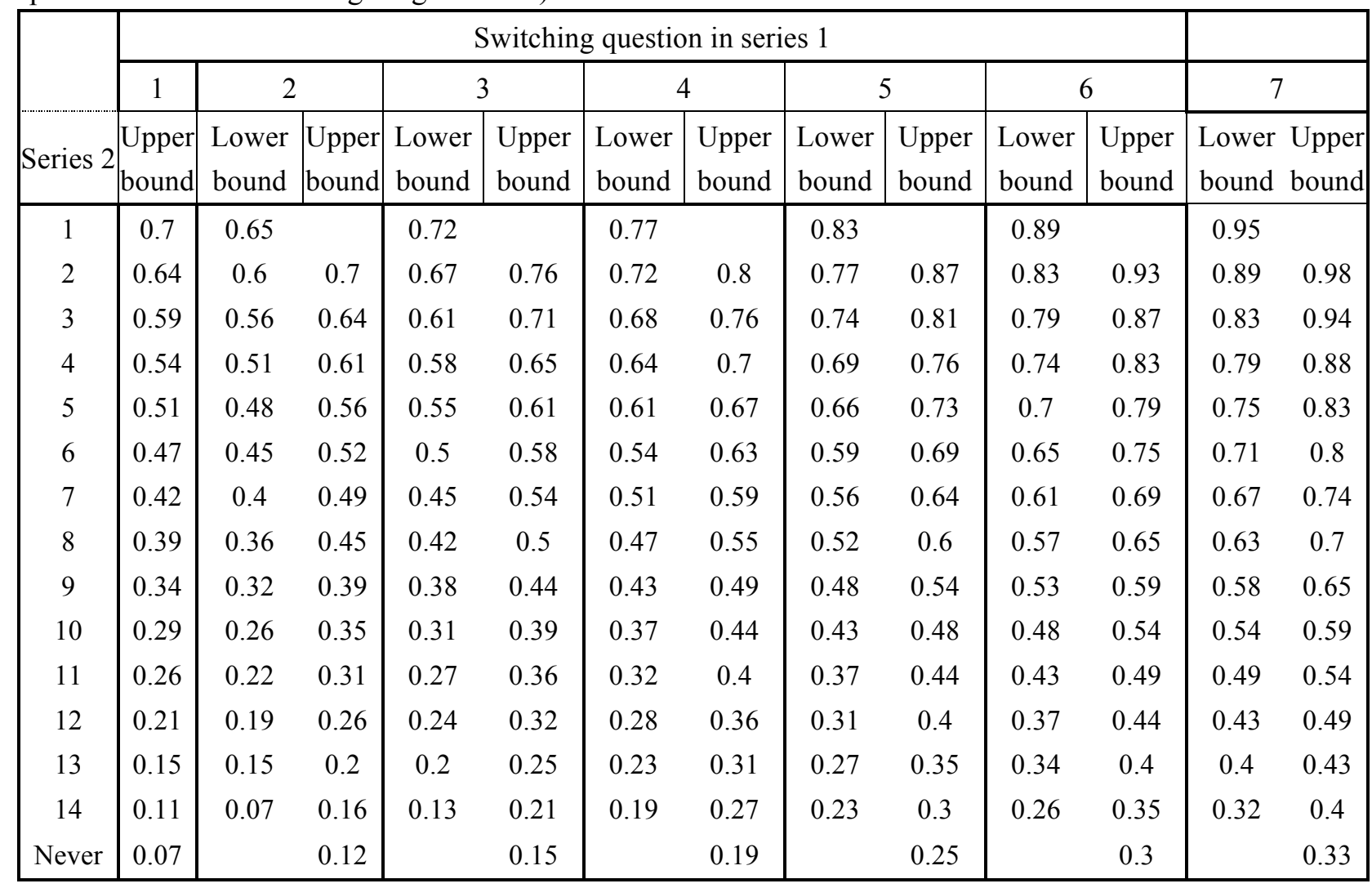

(cont.)

\begin{tabular}{|c|c|c|c|c|c|c|c|c|c|c|c|}
\hline \multirow[b]{2}{*}{ Series 2} & \multicolumn{2}{|c|}{8} & \multicolumn{2}{|c|}{9} & \multicolumn{2}{|c|}{10} & \multicolumn{2}{|c|}{11} & \multicolumn{2}{|c|}{12} & Never \\
\hline & $\begin{array}{l}\text { Lower } \\
\text { bound }\end{array}$ & $\begin{array}{l}\text { Upper } \\
\text { bound }\end{array}$ & $\begin{array}{l}\text { Lower } \\
\text { bound }\end{array}$ & $\begin{array}{l}\text { Upper } \\
\text { bound }\end{array}$ & $\begin{array}{l}\text { Lower } \\
\text { bound }\end{array}$ & $\begin{array}{l}\text { Upper } \\
\text { bound }\end{array}$ & $\begin{array}{l}\text { Lower } \\
\text { bound }\end{array}$ & $\begin{array}{l}\text { Upper } \\
\text { bound }\end{array}$ & $\begin{array}{l}\text { Lower } \\
\text { bound }\end{array}$ & $\begin{array}{l}\text { Upper } \\
\text { bound }\end{array}$ & $\begin{array}{l}\text { Lower } \\
\text { bound }\end{array}$ \\
\hline 1 & 1.01 & & 1.06 & & 1.1 & & 1.18 & & 1.23 & & 1.41 \\
\hline 2 & 0.94 & 1.05 & 1.01 & 1.09 & 1.05 & 1.14 & 1.12 & 1.19 & 1.16 & 1.26 & 1.35 \\
\hline 3 & 0.9 & 0.98 & 0.97 & 1.03 & 1 & 1.08 & 1.06 & 1.13 & 1.11 & 1.21 & 1.28 \\
\hline 4 & 0.86 & 0.92 & 0.92 & 0.97 & 0.95 & 1.03 & 1.02 & 1.08 & 1.07 & 1.15 & 1.22 \\
\hline 5 & 0.82 & 0.88 & 0.88 & 0.93 & 0.91 & 0.98 & 0.98 & 1.02 & 1.03 & 1.09 & 1.2 \\
\hline 6 & 0.77 & 0.85 & 0.83 & 0.9 & 0.86 & 0.95 & 0.93 & 0.97 & 0.97 & 1.05 & 1.14 \\
\hline 7 & 0.73 & 0.79 & 0.78 & 0.84 & 0.81 & 0.89 & 0.87 & 0.94 & 0.91 & 1 & 1.07 \\
\hline 8 & 0.68 & 0.75 & 0.73 & 0.8 & 0.76 & 0.86 & 0.82 & 0.91 & 0.86 & 0.96 & 1.03 \\
\hline 9 & 0.63 & 0.7 & 0.68 & 0.75 & 0.7 & 0.81 & 0.76 & 0.85 & 0.81 & 0.9 & 0.99 \\
\hline 10 & 0.59 & 0.65 & 0.63 & 0.7 & 0.65 & 0.76 & 0.71 & 0.79 & 0.77 & 0.84 & 0.91 \\
\hline 11 & 0.54 & 0.59 & 0.58 & 0.65 & 0.61 & 0.7 & 0.67 & 0.73 & 0.73 & 0.77 & 0.85 \\
\hline 12 & 0.49 & 0.55 & 0.53 & 0.59 & 0.55 & 0.64 & 0.62 & 0.67 & 0.67 & 0.73 & 0.81 \\
\hline 13 & 0.43 & 0.49 & 0.47 & 0.54 & 0.52 & 0.58 & 0.58 & 0.62 & 0.6 & 0.68 & 0.75 \\
\hline 14 & 0.38 & 0.46 & 0.42 & 0.48 & 0.45 & 0.52 & 0.52 & 0.59 & 0.54 & 0.63 & 0.67 \\
\hline Never & & 0.38 & & 0.42 & & 0.45 & & 0.52 & & 0.56 & 0.6 \\
\hline
\end{tabular}


Table A4. Switching point (question) in series 3 and the ranges of $\lambda$ (loss aversion parameter)

\begin{tabular}{|c|c|c|c|}
\hline Switching point & $\sigma=0.2$ & $\sigma=0.6$ & $\sigma=1$ \\
\hline 1 & $\lambda>0.14$ & $\lambda>0.20$ & $\lambda>0.29$ \\
2 & $0.14<\lambda>01.26$ & $0.20<\lambda>1.38$ & $0.29<\lambda>1.53$ \\
3 & $1.26<\lambda>1.88$ & $1.38<\lambda>1.71$ & $1.53<\lambda>1.71$ \\
4 & $1.88<\lambda>2.31$ & $1.71<\lambda>2.25$ & $1.71<\lambda>2.42$ \\
5 & $2.31<\lambda>4.32$ & $2.25<\lambda>3.73$ & $2.42<\lambda>3.63$ \\
6 & $4.32<\lambda>5.43$ & $3.73<\lambda>4.82$ & $3.63<\lambda>4.83$ \\
7 & $5.43<\lambda>9.78$ & $4.82<\lambda>9.13$ & $4.83<\lambda>9.67$ \\
\hline
\end{tabular}




\section{Appendix 4}

Table A5.Determinants of the trusters' expected return from trustees

\begin{tabular}{|c|c|c|c|c|c|}
\hline & OLS(1) & Tobit(2) & OLS(3) & IV-2SLS (4) & IV-Tobit(5) \\
\hline Dependant variable & $\begin{array}{l}\text { Expected } \\
\text { return }\end{array}$ & $\begin{array}{l}\text { Expected } \\
\text { return }\end{array}$ & Income & $\begin{array}{l}\text { Expected } \\
\text { return }\end{array}$ & $\begin{array}{l}\text { Expected } \\
\text { return }\end{array}$ \\
\hline South $(=1)$ & $\begin{array}{l}6.368 * * \\
(2.464)\end{array}$ & $\begin{array}{c}6.332 * * * \\
(2.370)\end{array}$ & $\begin{array}{l}20.158 * * * \\
(5.023)\end{array}$ & $\begin{array}{c}7.495 * * * \\
(2.661)\end{array}$ & $\begin{array}{c}7.481 * * * \\
(2.686)\end{array}$ \\
\hline $\begin{array}{l}\text { Probability weighting } \\
(\alpha)\end{array}$ & $\begin{array}{l}-0.239 \\
(3.427)\end{array}$ & $\begin{array}{l}-0.331 \\
(3.334)\end{array}$ & $\begin{array}{l}-2.001 \\
(5.589)\end{array}$ & $\begin{array}{l}-0.129 \\
(3.377)\end{array}$ & $\begin{array}{l}-0.236 \\
(3.490)\end{array}$ \\
\hline $\begin{array}{l}\text { Risk aversion } \\
(\sigma)\end{array}$ & $\begin{array}{c}3.014 \\
(3.568)\end{array}$ & $\begin{array}{c}3.033 \\
(3.543)\end{array}$ & $\begin{array}{l}-5.052 \\
(4.235)\end{array}$ & $\begin{array}{c}3.550 \\
(3.377)\end{array}$ & $\begin{array}{c}3.609 \\
(3.592)\end{array}$ \\
\hline $\begin{array}{l}\text { Loss aversion } \\
(\lambda)\end{array}$ & $\begin{array}{l}-0.440 \# \\
(0.268)\end{array}$ & $\begin{array}{l}-0.463^{*} \\
(0.265)\end{array}$ & $\begin{array}{l}0.471 \\
(0.387)\end{array}$ & $\begin{array}{c}-0.537 * * \\
(0.273)\end{array}$ & $\begin{array}{c}-0.560^{* *} \\
(0.282)\end{array}$ \\
\hline $\begin{array}{l}\text { Time discounting } \\
\text { rate (r) }\end{array}$ & $\begin{array}{c}28.623 \\
(82.623)\end{array}$ & $\begin{array}{c}32.889 \\
(78.499)\end{array}$ & $\begin{array}{l}-11.578 \\
(87.370)\end{array}$ & $\begin{array}{c}36.783 \\
(78.513)\end{array}$ & $\begin{array}{c}41.353 \\
(79.697)\end{array}$ \\
\hline $\begin{array}{l}\text { Present bias } \\
(\beta)\end{array}$ & $\begin{array}{c}1.442 \\
(7.946)\end{array}$ & $\begin{array}{l}1.008 \\
(7.680)\end{array}$ & $\begin{array}{l}10.234 \\
(9.241)\end{array}$ & $\begin{array}{c}0.162 \\
(7.613)\end{array}$ & $\begin{array}{l}-0.334 \\
(7.877)\end{array}$ \\
\hline $\begin{array}{l}\text { Number of } \\
\text { acquaintances }\end{array}$ & $\begin{array}{c}0.057 \\
(0.180)\end{array}$ & $\begin{array}{c}0.060 \\
(0.171)\end{array}$ & $\begin{array}{c}-0.822 * * \\
(0.351)\end{array}$ & $\begin{array}{c}0.142 \\
(0.199)\end{array}$ & $\begin{array}{c}0.147 \\
(0.200)\end{array}$ \\
\hline Age & $\begin{array}{l}-0.232 \\
(0.419)\end{array}$ & $\begin{array}{l}-0.273 \\
(0.402)\end{array}$ & $\begin{array}{l}0.798 \\
(0.586)\end{array}$ & $\begin{array}{l}-0.272 \\
(0.400)\end{array}$ & $\begin{array}{l}-0.313 \\
(0.407)\end{array}$ \\
\hline Age squared & $\begin{array}{l}0.004 \\
(0.004)\end{array}$ & $\begin{array}{l}0.004 \\
(0.004)\end{array}$ & $\begin{array}{l}-0.007 \\
(0.006)\end{array}$ & $\begin{array}{c}0.004 \\
(0.004)\end{array}$ & $\begin{array}{c}0.004 \\
(0.004)\end{array}$ \\
\hline $\operatorname{Female}(=1)$ & $\begin{array}{l}-2.507 \\
(1.721)\end{array}$ & $\begin{array}{l}-2.541 \\
(1.643)\end{array}$ & $\begin{array}{l}-1.544 \\
(3.148)\end{array}$ & $\begin{array}{l}-2.134 \\
(1.749)\end{array}$ & $\begin{array}{l}-2.151 \\
(1.787)\end{array}$ \\
\hline $\begin{array}{l}\text { Years of } \\
\text { education }\end{array}$ & $\begin{array}{l}0.020 \\
(0.221)\end{array}$ & $\begin{array}{c}0.020 \\
(0.209)\end{array}$ & $\begin{array}{c}0.367 \\
(0.259)\end{array}$ & $\begin{array}{c}0.021 \\
(0.220)\end{array}$ & $\begin{array}{c}0.021 \\
(0.222)\end{array}$ \\
\hline $\begin{array}{l}\text { First job being in } \\
\text { agriculture }(=1)\end{array}$ & $\begin{array}{l}-2.110 \\
(1.951)\end{array}$ & $\begin{array}{l}-2.291 \\
(1.866)\end{array}$ & $\begin{array}{l}-5.592 \\
(4.278)\end{array}$ & $\begin{array}{l}-1.930 \\
(1.969)\end{array}$ & $\begin{array}{l}-2.102 \\
(2.003)\end{array}$ \\
\hline $\begin{array}{l}\text { Having a second } \\
\text { job }(=1)\end{array}$ & $\begin{array}{c}2.154 \\
(1.955)\end{array}$ & $\begin{array}{c}2.286 \\
(1.878)\end{array}$ & $\begin{array}{c}0.624 \\
(2.562)\end{array}$ & $\begin{array}{l}1.740 \\
(1.881)\end{array}$ & $\begin{array}{l}1.857 \\
(1.922)\end{array}$ \\
\hline $\begin{array}{l}\text { Total income } \\
(/ 1000)\end{array}$ & $\begin{array}{l}-0.011 \\
(0.040)\end{array}$ & $\begin{array}{l}-0.010 \\
(0.038)\end{array}$ & - & $\begin{array}{c}0.110 \\
(0.110)\end{array}$ & $\begin{array}{c}0.114 \\
(0.114)\end{array}$ \\
\hline Relative income & $\begin{array}{l}1.203 \\
(1.919)\end{array}$ & $\begin{array}{c}1.242 \\
(1.812)\end{array}$ & $\begin{array}{l}41.368^{* * * *} \\
(2.906)\end{array}$ & $\begin{array}{l}-3.862 \\
(4.618)\end{array}$ & $\begin{array}{l}-3.972 \\
(4.795)\end{array}$ \\
\hline $\begin{array}{l}\text { Amount of international } \\
\text { remittances }(/ 1000)\end{array}$ & $\begin{array}{c}-0.375 * * * \\
(0.075)\end{array}$ & $\begin{array}{c}-0.375 * * * \\
(0.072)\end{array}$ & $\begin{array}{l}-0.039 \\
(0.194)\end{array}$ & $\begin{array}{c}-0.385 * * * \\
(0.077)\end{array}$ & $\begin{array}{c}-0.384 * * * \\
(0.078)\end{array}$ \\
\hline $\begin{array}{l}\text { Amount of domestic } \\
\text { remittances }(/ 1000)\end{array}$ & $\begin{array}{c}0.174 \\
(0.508)\end{array}$ & $\begin{array}{c}0.198 \\
(0.483)\end{array}$ & $\begin{array}{l}-0.555 \\
(0.726)\end{array}$ & $\begin{array}{c}0.157 \\
(0.481)\end{array}$ & $0.180(0.487)$ \\
\hline Average rainfalls & - & - & $\begin{array}{c}18.058 * * * \\
(3.060) \\
\end{array}$ & - & - \\
\hline Number of observations & 156 & 156 & 156 & 156 & 156 \\
\hline $\begin{array}{l}\text { Number of left censored } \\
\text { observations }\end{array}$ & & 3 & 3697 & & 3 \\
\hline Wald test of exogeneity & & & & 0.304 & 0.252 \\
\hline $\mathrm{R}^{2}$ & 0.172 & 0.024 & 0.893 & 0.144 & - \\
\hline
\end{tabular}

Notes: a) These regressions include only 156 observations due to a lack of information regarding income and remittances for 10participants in the 2002 household survey data. b) Standard errors are in parentheses. c) *** indicate significance at the $1 \%$ level ,** at the $5 \%$ level, * at the $1 \%$ level, and $\#$ at the $10.4 \%$ level. 